\title{
Price adjustments by a gasoline retail chain*
}

by

\author{
Marcus Asplund, Rickard Eriksson, and Richard Friberg \\ Department of Economics \\ Stockholm School of Economics \\ Box 6501, 11383 Stockholm
}

This version: August 19, 1997

\section{Working Paper Series in Economics and Finance No 194}

September 1997

\begin{abstract}
This paper provides a detailed examination of price responses in the Swedish gasoline market to changes in the world market price. We use daily price data from one of the leading retail chains together with input costs (spot market price and exchange rate) for the period January 1980 to December 1996. Over the period the list price was increased (decreased) 130 (120) times, but the periodicity varies substantially and there are very few small price adjustments. This pattern is broadly consistent with a statedependent pricing rule. Predictions of a simple Ss-model are tested with an ordered probit sample selection model. The results show that price adjustments are more likely to occur when either the input price or the exchange rate has moved significantly since the last price adjustment. However, our results indicate that prices are not adjusted to the long run equilibrium price at once. Therefore we explore an error correction model (ECM), that shows that in the short run prices are gradually moving towards the long run equilibrium in response to cost shocks.
\end{abstract}

Key words: Price adjustment; sticky prices, price rigidities; exchange rate passthrough; ordered probit sample selection; error correction model; gasoline market.

JEL classification: C22; C24; C25; E31; F14; L71.

\footnotetext{
* We would like to thank seminar participants at the Stockholm School of Economics and Anders Vredin for valuable comments. Thanks also to Lena Backlund and Anna Erman, Kuwait Svenska Petroleum, Anna Nord, Svenska Statoil, Leif Persson, OK, Britta Röjnemark, JET, Roland Erlandsson, Norsk Hydro, and Kjell Nygren, Preem. Discussions with Gösta Bergbom, Shell, have been particularly valuable. Financial support from Bankforskningsinstutet, The Swedish Competition Authority, Ragnar Söderbergs Stiftelse and Riksbankens Jubileumsfond is gratefully acknowledged.
} 


\section{Introduction}

In this paper we study the pass-through of cost changes to retail prices in the Swedish gasoline market. We use 17 years of daily retail gasoline prices from one of the major retail chains. These data provide an unusually clean case to test hypotheses about how firms react to changes in the underlying costs of inputs, since both price and costs are observable on a daily basis. For the same period and frequency we have spot market prices of gasoline (quoted in US dollars) in Rotterdam and the exchange rate between Swedish kronor and US dollars. Even though both the input price and the exchange rate exhibit daily fluctuations the retail price is rigid in the short run. In the longer run, however, prices appear to follow the cost movements quite closely. Much of the paper is concerned with the details of price adjustment and in particular the decision to adjust. In the second part of the paper we study the long-run pass-through of costs.

Figure 1 shows the relationship between price and costs in the Swedish gasoline market for the sub-period July-September, 1995. Output price remains fixed for some period of time and when it is adjusted it is in the direction motivated by the underlying variable. This pattern can be regarded as typical for prices of individual products. The stickiness of prices is a well known phenomenon and has been the focus of considerable theoretical and empirical attention (see Blanchard and Fisher (1989, p. 372-426) and Mankiw and Romer (1991) for overviews). Below we use figure 1 to illustrate how some of the methodological and data problems that previous studies have encountered can be categorized. Of course, this does not mean that they are uninformative, but rather points to factors to be kept in mind when discussing the results and what they tell us about price setting behaviour.

Figure 1 about here

Our work is related to a set of recent empirical papers that have been concerned with price adjustments in response to cost changes. Awh and Primeaux (1992) use annual price data from electric utilities and measure cost by total operating expenditure. Dahlby (1992) uses quarterly data on insurance premiums and Kraft (1995) annual price indexes for two digit German industries, and both control for cost 
with wage indexes. A common feature of these studies is that the data have low frequency which in Figure 1 corresponds to a situation where prices and cost are only observed with long intervals. Moreover, often the prices are average market prices whose development will be smoother than prices set by individual firms.

Another line of research uses quoted prices of specific products and are primarily interested in how often prices are adjusted in response to inflation. Cecchetti (1986) studies the prices of magazines and Kashyap (1995) studies prices in retail catalogs (issued approximately every sixth month). Lach and Tsiddon (1997) provide evidence of the timing of price adjustment of food products and beverages in Israel. In comparison with the data depicted in Figure 1 the price is measured accurately but the development of costs are unobserved in so far as they differ from the general level of inflation.

The relatively clean data on input and output prices have made gasoline prices the subject of many studies of price adjustments. Some recent examples include Bacon (1991), Borenstein et al (1997) and Slade (1992). Additional references are given in Duffy-Deno (1996). However, all studies that examine a longer time period use price data aggregated to regional or national levels. Again referring to figure 1, information about when an individual firm chooses to change its price is lost.

The variability of exchange rates has spurred a growing literature that studies the pass-through of exchange rate changes into import prices. Menon (1995) provides a survey. The papers generally use unit value data (total customs declared value of imports divided by the quantity of imports in the industry) and do not consider other cost shifters than the exchange rate. This makes them vulnerable to the same types of criticism that can be directed against the papers mentioned above. There is a lack of detailed case studies of individual markets (Goldberg's (1995) study of the U.S. automobile market is one exception).

A recurring theme in the literature is whether price adjustments are symmetric with respect to some underlying variable(s). For example Borenstein et al (1997) are interested in whether gasoline prices are more flexible upwards than downwards. Feenstra (1989) tests if the long-run pass-through of tariffs and exchange rates onto prices of Japanese cars, trucks and motorcycles in the US market are equal. In this paper we study various types of symmetry, e.g. upwards and downwards flexibility of prices, symmetry in response to input costs and taxes. 
The paper is organised as follows. Section 2 sketches a theoretical model of price setting when there are fixed adjustment costs. Section 3 describes the market and defines the variables used. It also provides a first look at the behavior of prices, costs and time between price adjustments. Section 4 contains our econometric analysis. We employ both a technique that corresponds closely to our theoretical model (an ordered probit sample selection model) as well as an error correction model. Section 5 concludes and discusses our results.

\section{A theoretical framework}

There are a large number of theories that try to explain why prices would be fixed in response to small shocks in some underlying variable. Several of them do not offer predictions for how the price should be adjusted for example models building on a kinked demand curve. One of the most important theories that actually does present hypothesis for how prices are adjusted is the Ss-model, where Barro(1972) is one of the earliest references. The central argument rests on fixed costs of price adjustments, which implies that prices remain fixed for minor disturbances. When the underlying stochastic variable follows a random walk with no drift, the price will be adjusted back to the static optimum whenever the stochastic variable passes an upper bound (S) or a lower bound (s). At a first glance the Swedish gasoline industry seems to correspond closely to the assumptions of the simple Ss-model. We can not reject that input prices follow random walks during the sample period (see section 3) and the good can be analyzed as being non-storable. ${ }^{1}$

To formalize the ideas we sketch a simple Ss-model of price setting when there are shocks to two cost variables and demand is linear with slope $b .^{2}$ Assume that if the price was set to maximize contemporaneous operating profits in each period, the maximization problem would be given by

\footnotetext{
${ }^{1}$ Further, adjustment seems to take place by changing the retail price rather than changing other decision variables such as the quality or terms of delivery of the good (which Carlton (1986) found to play a significant role on the markets that he studied).

2 The model is based on the Blanchard and Fischer (1989, p. 402) rendition of Barro's (1972) state dependent price setting model.
} 


$$
\max _{P_{t}}\left(R P_{t}-S P_{t} E_{t}-T A X_{t}\right)\left(1-b R P_{t}\right)
$$

where $S P, E$ and $T A X$ represent cost variables and $R P$ represents the retail price. The optimal per period price, denoted by an asterisk, is the standard monopoly price

$$
R P_{t}^{*}=\frac{1}{2 b}\left(1+b\left(S P_{t} E_{t}+T A X_{t}\right)\right)
$$

In a frictionless world this is the price that we would observe at every moment. Assume now that there is a fixed cost, $f$, associated with price changes. Suppose that price at time $t$ is set optimally for some values of $S P_{t}, E_{t}$ and $T A X_{t}$ and further that at time $t+n$ they have changed with $\triangle S P, \Delta E$ and $\triangle T A X$. Let $S P$ and $E$ follow random walks whereas $T A X$ is non-stochastic. Denote by $L$ the opportunity cost of keeping prices fixed in the face of cost changes. A little algebra gives that the loss function is

$$
L_{t+n}=\frac{b}{2}\left(E_{t} \Delta S P+S P_{t} \Delta E+\Delta S P \Delta E+\Delta T A X\right)^{2} .
$$

Price will adjust when the opportunity cost of not adjusting the price $L$, reaches some threshold level. The opportunity cost depends on the change in costs since the last time that price was set.

How much will then the price change when it actually does change? When costs follow random walks their current values summarize all relevant information for predicting tomorrow's values. Therefore in a period when the price changes the resulting price will only be dependent on the current costs. Let $\Delta R P^{*}$ denote the difference between the optimal price that was set at time $t$ and the optimal price that is set at time $t+n$, when costs have drifted far enough to motivate a price adjustment. It is easily shown that

$$
\Delta R P^{*}=\frac{1}{2}\left(S P_{t} \Delta E+E_{t} \Delta S P+\Delta T A X+\Delta S P \Delta E\right) .
$$


Figure 2 below gives a simple representation of the adjustment pattern of the price that we would expect based on fixed costs of adjustment. When the opportunity cost of not adjusting price has drifted far enough, a threshold is reached and the firm adjusts its price. Since the adjustment cost is independent of the size of the change, the firm will adjust to the static optimum once it finds that the benefit of changing its price outweighs the cost of doing so.

Figure 2 about here

Adding more realism to the model is certainly possible. Unfortunately the tractability decreases sharply. Nevertheless we will offer some qualitative predictions about adjustment patterns under some different assumptions. The above pattern clearly relies on fixed adjustment costs. If we instead only had quadratic adjustment costs (no fixed cost) price should be adjusted every period (analogous to the argument in e.g. Gagnon and Knetter (1995) and Kasa (1992)). We would observe a partial adjustment pattern, since it is less costly to change the price in several small steps instead of in one large leap. With a combination of fixed and quadratic adjustment costs one would find no small price adjustments and a gradual adjustment pattern when there are large shocks. ${ }^{3}$

The simple form that equation (4) takes hinges on that we assume that the firm acts as a monopolist facing a linear demand function. Thus we disregard that there are competitors in the market who will be affected by the same cost shocks. More generally, the pass-through of cost changes to prices depends on how the demand elasticity changes as the price changes and on the cost shocks of competitors. ${ }^{4}$

Keeping the limitations of the stylized model in mind, equations (3) and (4) form the basis for our econometric specification in section 4.1. We predict that price adjustment is more likely to occur the further costs and taxes have drifted since the last price adjustment. More specifically the opportunity cost should be dependent on the squared drift(s). Price adjustment, when it does take place, will be dependent only on the drift. If we find that current price adjustment is explained by cost changes prior to the previous adjustment, this is inconsistent with only fixed adjustment costs.

\footnotetext{
3 We are aware of no model that analyzes the effects of a combination of fixed and variable adjustment costs on pricing decisions. One way of proceeding would be along the lines of Dixit and Pindyck (1994, p. 381-391).
} 


\section{Market and data description}

We study the price of leaded premium gasoline to consumers in Sweden for the period January 1, 1980 to December 31, 1996. Gasoline is almost exclusively sold by branded stations and prices in the retail market are determined by the list prices of retail chains (from now on refereed to as "firms"). In this respect the Swedish gasoline market is thus quite different from the one in e.g. the United States (see Borenstein et al (1997)), where vertical integration is much less prevalent. The quantity of gasoline sold annually has increased slightly over the period (from $4913^{\prime} \mathrm{m}^{3}$ in 1980 to $5682^{\prime}$ $\mathrm{m}^{3}$ in 1996). Firm concentration shows a weak tendency to rise, the Herfindahl-index has increased from 0.127 in 1980 to 0.152 in 1996. Some previous studies (e.g. Neumark and Sharpe (1992), Weiss (1993)) have tested if market structure has an effect on the nature of price adjustment. We have tested if firm concentration significantly influenced the long-run equilibrium prices (reported in (5) below) but found no evidence that the small increase in concentration had any measurable effect.

From January 1990 and onwards the data set includes prices for virtually all the retail chains (the seven firms in the sample represent $94.5 \%$ of sales in 1996). For the period from January 1980 to December 1989 price data are available for two of the firms (Shell and Norsk Hydro).We restrict our attention to the retail list price of one of the firms, Shell, which throughout the period is either the largest or the second largest firm (with a market share of 16.5-21.0\%). ${ }^{5}$ The behavior of Shell's retail price is representative for the prices of other firms, since more often than not, firms' list prices are identical and they all adjust their prices within a day or two. ${ }^{6}$ Even though the prices are more or less identical for a retail chain across the country (save for some minor differences due to transport costs) there is some local variation in retail prices. The local variation refers to constant differences in price levels and not to differences in the pattern of price adjustments.

\footnotetext{
${ }^{4}$ See e.g. Feenstra, Gagnon and Knetter (1996).

5 Swedish Petroleum Institute Annual Report, various issues.

${ }^{6}$ Clearly this is not a perfectly competitive market in the sense that the demand for a firm's product instantaneously disappears if it charges a higher price than competitors (e.g. due to localization of the retailers). Issues regarding strategic interaction (in particular firms' ability to co-ordinate their price changes) will be addressed in some future work.
} 
The chain from input price to consumer price is very simple in Sweden. For the firms the relevant input price is the Rotterdam spot price for gasoline. Some firms buy their gasoline at this price in the spot market, but even those who operate their own refineries claim to use it as the transfer price between the producing and the selling divisions.

\subsection{Variable definitions and sample period}

We study the retail price divided by $(1+\mathrm{VAT})$ which is denoted $R P$. This price is observed every day and can, in principle, be adjusted any day. The Rotterdam spot market price of gasoline in USD, SP, and the SEK/USD exchange rate, $E$, are not quoted on weekends and public holidays. We assume these variables to be unchanged during these days. The marginal cost of gasoline in SEK is denoted $M C$ and defined as $S P^{*} E$. Table 1 below defines all the variables and gives the data sources. The price changes are denoted $\triangle R P$ and changes in marginal cost $\triangle M C$. For some of our regressions we separate $\triangle M C$ into movements in the exchange rate, $\Delta E^{*} S P(-1)$ and spot price $\Delta S P^{*} E(-1)$ according to the definition in Table 1 . Another variable of prime importance is the quantity tax, denoted TAX, which in 1996 accounted for about $50 \%$ of the retail price. Figure 3 shows the development of $R P, M C$ and $T A X$ over the sample period.

Table 1 about here

Figure 3 about here

We have identified three price wars (partly from information in the documents given to us by the companies), January 2, 1984 - February 21, 1984, April 2, 1988 May 6, 1988 and September 30, 1993 - October 28, 1993. For the purpose of this paper it is natural to exclude the price war periods since our interest is in the relation between costs and prices, and during periods of price wars price changes do not reflect costs changes (one episode is illustrated in Figure 4 ). ${ }^{7}$ We drop from our sample the

\footnotetext{
${ }^{7}$ Several recent empirical papers (e.g. Borenstein and Shepard (1996), Ellison (1994), Slade (1992)) have dealt with the causes and timing of price wars. Casual inspection of the three episodes in our sample revealed no apparent explanation to why they occurred. It could certainly be interesting to
} 
period beginning the day after the last price adjustment prior to the price war and ending the day after the price increase that ends the price war. The period August 29, 1986 -August 23, 1987 is excluded because of a legally imposed price freeze.

Figure 4 about here

\subsection{Descriptive statistics}

Much of the recent literature on pricing has been concerned with the distribution and frequency of price adjustments. The possible asymmetry between price increases and decreases has been an intensely debated question. To add to the evidence on the behavior of prices we begin by a fairly detailed description of the distribution of price adjustments, before we relate them to cost changes. Even though our sample contains 250 price adjustments they are quite infrequent (roughly once every third week). For the sample there are about the same number of price increases as price decreases and their sizes are of the same magnitude as seen in Table 2. Thirteen of the price adjustment are associated with tax changes and correspond to the largest price increases. These price adjustments are different from the other price adjustments in some aspects, primarily because tax changes are known by the firms in advance. Excluding these results in 117 upward and 120 downward price adjustments, with a mean adjustment of 7.59 for increases and -6.62 for decreases . Considering that the data contains seventeen years of which several had high general inflation this may seem surprising. However, the retail price of gasoline is largely determined by the highly volatile spot market price (in USD) and the likewise volatile SEK/USD exchange rate, which together resulted in the input cost in SEK being almost the same in 1980 as in 1996.

Table 2 about here

Figure 5 about here

study the price wars in more detail but any econometric attempts to predict three price wars during seventeen years are likely to be unsuccessful. 
Additional evidence on the symmetry of the distribution of price changes is given by Figure 5. The size distribution of price increases is similar to that of price decreases. Thus there is no apparent asymmetry such as price decreases being smaller or larger. The figure also points at one important feature of the adjustments, namely that there is a minimum absolute size of $|\Delta R P|=2$. This strongly indicates that there is some fixed cost associated with price changes that keeps firms from making very small adjustments. ${ }^{8}$ Moreover, conditional on $|\Delta R P|>>2$, small adjustments are more frequent than large ones. All adjustments larger than $|18|$ are associated with tax changes or large discrete changes in $E$ due to devaluations of the Swedish krona ${ }^{9}$. The next important fact is the existence of absolute changes of quite different magnitude in this interval (between $|2|$ and $|18|)$. The size of the price adjustments and the time between them is not stable over time. Table 3 shows that there are more adjustments which on average are smaller in size in the 90's than in the 80's. Although this is the case there is considerable variability of the size of adjustment, also within subperiods. The frequency of price adjustments increases around 1990. The average time between two price adjustments is less than half in the 90's compared to the previous decade.

Table 3 here

Further evidence of the timing arise from breaking down price adjustments into the day of the week and month of the year as we do in Table 4. Firstly, for the gasoline market there is some seasonal variation in sales over the year with a peak in the summer months. If there are fixed costs of adjusting price, but the loss of having a misadjusted price is proportional to the sales volume, one would expect to find relatively more adjustments during the high demand months (holding marginal costs constant). This is not borne out by the table but could be an interesting method to determine the nature of adjustment costs in markets with a more pronounced seasonal pattern. Secondly, we find substantial differences in the number of price adjustments over the week, with few adjustments on Saturdays, Sundays, and Mondays. Of course

\footnotetext{
${ }^{8}$ Carlton (1986) reports similar findings for petroleum products. 1 precent of the price adjustments changed the price less than $1 / 4$ percent, 9 precent of the price adjustments changed the price less than 1 percent and 47 precent of the price adjustments changed the price less than 2 percent.

${ }^{9}$ Sweden had a fixed exchange rate against a basket of currencies in which the USD was included until May 17, 1991. Even though the USD was included in the basket, $E$ exhibited large fluctuations.
} 
the pattern may have several explanations. The most convincing one is that financial markets and the Rotterdam spot market are closed on Saturdays and Sundays and thus no new information arrives on these days. ${ }^{10}$

Table 4 here

We now turn to an investigation of the relationship between price and cost. As a first step we use monthly data to estimate the long run relationship in levels between $R P$ and the explanatory variables $M C, T A X$ and $W A G E$. WAGE is an index of the nominal wage but is not measured in the same units as the others and the coefficient is therefore not readily interpreted. This regression fills a dual purpose. First, the high explanatory value of the regression indicates that these three variables are able to explain almost the entire variation in price. Second, the estimated error term will be used as input in later regressions. The estimated relationship is

$$
\begin{aligned}
& R P=22.9+0.902 * M C+0.658 * T A X+2.01 * W A G E+u \\
& \quad(6.26)(0.03) \\
& D-W: 0.63 \quad \text { adj. } \mathrm{R}^{2}: 0.988
\end{aligned}
$$

In the long run there is a near one-to-one relationship between $R P$ and $M C$. Over the period $T A X$ and $W A G E$ both increase more or less monotonically and the resulting high correlation explains the low coefficient on $T A X$. Not surprisingly the Durbin-Watson statistic shows evidence of positively autocorrelated error terms. This suggests that periods with relatively high prices tend to be followed by another period of relatively high prices, and vice versa.

Most (if not all) theories of price adjustments agree that there should be a non negative relation between recent cost changes and price adjustments. ${ }^{11}$ Our data

\footnotetext{
10 Throughout the paper we assume that the firms set the price in response to the costs the preceeding day. This gives better estimates than assuming that prices are set in response to the cost the current day. It is also consistent with the few price adjustments made on Mondays.

${ }^{11}$ In general one could argue that some price adjustments are done in anticipation of changes in underlying cost variables. For a product such as gasoline this is probably not correct. The reason being that it is well known that asset prices in liquid markets (such as the foreign exchange market and spot market for gasoline) are intrinsically unpredictable, i.e. follow random walks. Augmented Dickey Fuller tests for random walks in our data on $E$ and $S P$ confirm this presumption. This is important for
} 
suggest that this is true on average, but that there are considerable deviations from this in many cases. The means and medians of $\triangle M C$ have the expected signs for $\triangle R P>0$ and $\triangle R P<0$ respectively. It is interesting to note that average $\triangle M C$ is of roughly the same absolute size for both price increases and decreases. ${ }^{12}$ Although the expected relation between $\triangle M C$ and $\triangle R P$ holds for the means and medians, the minimum and maximum values of $\triangle M C$ show that sometimes the price is reduced when the marginal cost has increased significantly. We illustrate this in Figure 6 where one expects no observations in the second and fourth quadrant. In fact, about one fifth of the price adjustments are in these two quadrants. Although this could be explained by omitted variables in the marginal cost measure this is probably not the case here. The reason is that if any important cost variables are omitted we would arguably get far lower explanatory power in regression (5). This was also illustrated in Figure 3.

Figure 6 about here

As a first pass at an econometric description of the relationship between price adjustment and marginal cost changes, we fit $\triangle R P$ on $\triangle M C$ and $\triangle T A X .{ }^{13}$ In addition we estimate separate OLS-regressions for price increases and price decreases. Doing this we ignore complications such as sample selection bias and the possible influences of past cost changes, which are discussed in detail in section 4.1 and 4.2. The results are

$$
\begin{aligned}
& \Delta R P=0.420+0.553 * \Delta M C+0.889 * \Delta T A X \\
& \begin{array}{lll}
(0.40) & (0.043) \quad(0.0466)
\end{array} \\
& \operatorname{adj.} R^{2}: 0.679 \quad(6) \\
& \Delta_{+} R P=5.96+0.267 * \Delta M C+0.795 * \Delta T A X \\
& \begin{array}{lll}
(0.43) & (0.0428) \quad(0.0318)
\end{array} \\
& \operatorname{adj.} R^{2}: 0.832 \quad\left(6^{\prime}\right) \\
& \Delta \_R P=-5.80+0.165 * \Delta M C \\
& \text { (0.38) (0.0444) } \\
& \operatorname{adj} . R^{2}: 0.098 \quad(6 ”)
\end{aligned}
$$

\footnotetext{
our econometric work since we do not need to construct forward looking cost variables, since all information is incorporated in the current values of $E$ and $S P$.

12 We postpone the discussion of the relative effects of $\Delta S P^{*} E(-1)$ and $\Delta E^{*} S P(-1)$ until sections 4.1 and 4.2 .

$13 \triangle W A G E$ is not used as an explanatory variable since it is only observed monthly and price adjustments do not have a fixed frequency. Moreover, this series shows very little variation and is difficult to separate from a trend variable.
} 
The regressions (6)-(6') are displayed in Figure 6. Using all price changes, as in equation (6), we find that the constant is not significantly different from zero. Further, we note that about half of the change in $M C$ since the last price change is reflected in today's price change. The coefficient on $\triangle M C$ is 0.267 for price increases and 0.165 for price decreases. The absolute size of the constant in (6') and (6', ) is the same and significantly different from zero. This is a reflection of the fact that there is a minimum absolute size of price changes. Thus, pooling all price changes will result in a bias towards a steeper slope of the regression line compared to the slopes conditional on the direction of the adjustment. The explanatory power of (6") is much lower than for (6'). One explanation for this is that we are very succesful in estimating the effects of tax changes. As mentioned above, the sample selection bias is ignored in (6)-(6"). We adress this problem in the next section. 


\section{Econometric results}

\subsection{Daily frequency}

We now attempt to estimate when, and how much, firms adjust prices using daily data and a sample selection model. The 250 out of 5732 days when the firm decided to adjust its price is presumably not a random sample of days. Neither are the days when the price is increased (decreased) a random draw from the days when the price was adjusted. Based on an input cost variable there is a natural ranking between three mutually exclusive alternatives. When there has been a large downward movement in costs we are more likely to observe a price decrease; for small movements the price is likely to be held constant; and finally for large positive movements we expect to see the price increase. Ignoring the sample selection problem may lead to biased estimates in a regression with the size of adjustments as dependent variable. Therefore we employ an econometric technique similar to the well known Heckman (1979) two-stage procedure. ${ }^{14}$ First, estimate the probabilities for the price being decreased, held constant, or increased. Second, estimate the size of price increases and price decreases in separate regressions, using the probabilities estimated in the first step to control for the sample selection problem. More formally, the first stage selection mechanism is an ordered (rather than a standard binary) ${ }^{15}$ probit model and the second stage, the price change regression, is an ordinary least squares estimator with a correction for sample selection.

The magnitude of the price adjustment can only be observed when the price is increased or decreased and is then determined by the regression model

$$
\Delta R P=\beta_{j}^{\prime} \mathbf{X}_{j}+\varepsilon \quad \text { for } \mathrm{j}=\text { decrease or increase }
$$

where $\beta$ is a vector of parameters and $\mathbf{X}$ are explanatory variables, which are allowed to be different for increases and decreases. As discussed and defined in Appendix 1, the

\footnotetext{
14 This methodology captures the idea that the firm's decision to adjust price is done in two steps. First it decides whether to decrease, hold constant or increase the price. Second, conditional on this, it decides on the size of the adjustment.

15 The problem with a binary choice model (used e.g. in Slade (1995)) for the decision to adjust price is easy to explain with an example. When e.g. the cost has decreased we expect price to be adjusted downward, and vice versa. With the dependent variable being one when the price is adjusted (upwards or downwards) a positive (negative) coefficient of the change in cost implies that positive movements in the costs increase both the probability that the price will increase and decrease.
} 
expectation of the error term in (7) is $E[\varepsilon \mid Z=j]=\rho \sigma \lambda$, where $\lambda$ is a parameter related to the sample selection bias.

To give a broad picture of the data and of the limitations of the theoretical models we estimate several specifications. If the price is adjusted back to the static optimum then the movements in the explanatory variables since the last adjustment should be included in the ordered probit and OLS regressions. First, we follow the approach in the previous section and estimate a model with $\triangle M C$ and $\triangle T A X$. Second, following more closely the theoretical model in section 2, a specification with the two components of $\triangle M C ; \triangle S P^{*} E(-1)$ and $\triangle E^{*} S P(-1)$ together with $\triangle T A X$. One deviation from the theoretical model is that $\triangle M C$ is included in the ordered probit regressions together with the signed square term of the movements, $(\Delta M C)^{2}=\operatorname{sign}(\Delta M C) * \Delta M C * \Delta M C$.

The results are reported in the first three columns in Table 5 and Table 6 respectively. ${ }^{16}$ The coefficient of $\Delta M C$ is positive while $(\Delta M C)^{2}$ is negative in the ordered probit regression. Thus it is more (less) likely that the price is increased (decreased) when the marginal cost has increased since the last price adjustment. However, it is proportionally less likely that firms adjust prices at large marginal cost changes. The marginal effects of $\triangle M C$ and $(\triangle M C)^{2}$ are small but in all the reported regressions they are essentially symmetric, e.g. evaluated at the means the marginal effect of $\triangle M C$ are -0.0028 and 0.0028 on the probability of a price increases and decreases respectively. This suggests that there is no evident asymmetry in the decision to adjust the price upward and downward in response to changes in marginal cost. Because the observations to about $95 \%$ consists of days when the price is held constant it will be quite difficult to predict exactly which day it will be adjusted and the predictive ability is naturally poor. ${ }^{17}$ In what follows this implies that the sample selection parameter we suspect is important in the OLS regression will have little variation across days. Turning to the OLS regression we find that for both price increases and decreases only about 0.28 of $\triangle M C$ is reflected in the price adjustment.

\footnotetext{
16 For the econometric estimation we have used the software LIMDEP and the procedure stated in the 7.0 Manual (1995 p.656-659). There are some typos in the manual. The definitions of U2, U3, XG should be Part(B,KP1,KP1), [10000], [XG1,XG2] respectively. Finally, the first definition of VC should be renamed and used in place of $\mathrm{VC}$ in the following.

${ }^{17}$ Reducing the frequency to weekly data gives higher predictive power, but the measure of the timing of the adjustment becomes less precise.
} 
This is in line with (6') and (6') but in sharp contrast to the regression where all price adjustments were pooled (6) which yielded a coefficient of 0.55. As illustrated in Figure 5, the difference in point estimates is explained by the existence of a minimum absolute size of adjustments. Compared to (6") the significance levels of the coefficients are considerably lower in the OLS regressions for price decreases in Table 5 due to the low variation in the sample selection variable $\lambda$. Finally, the effects of tax changes in the regressions, show that prices are more likely to be adjusted upwards when there has been an increase in taxes $(D T A X=1)$ and the coefficient of the size of the tax adjustment $(\triangle T A X)$ is about 0.8 for price increases.

When $\triangle M C$ in Table 6 is decomposed into $\Delta S P^{*} E(-1)$ and $\Delta E * S P(-1)$ each of them has the expected sign for price increases and decreases in both the ordered probit and OLS regressions. The most noteworthy in the ordered probit regression is that a Wald test can not reject that the two are equal at the $10 \%$ level. On the other hand, in the OLS regression for price increases the coefficient on $\Delta E^{*} S P(-1)$ is higher at the $10 \%$ level. Thus a given change in the marginal cost leads to a greater price increase if it stems from the exchange rate than from the spot market price. Again, however, the significance levels in the OLS regressions are low.

The low point estimates of $\triangle M C$ in relation to the almost complete pass through of $M C$ in the long run raise doubts about the econometric specification. We therefore introduce additional variables in our attempt to estimate the size of price adjustments. First, lagged variables are included to account for the possibility that price adjustments partly reflect previous changes in the cost variables. Second, to account for any potential asymmetry in responses to upward and downward movements in cost variables we separate $\triangle M C$ into $\triangle_{+} M C$ and $\triangle M C$. Likewise, the last change, $\triangle M C_{-l}$, is split into $\Delta_{+} M C_{-l}$ and $\Delta M C_{-l}$. Finally, we include the estimated error from the long run relation between $R P$ and $M C, T A X$ and $W A G E$, which in Section 3 was denoted $\hat{u}$. This is done to account for the possibility that both the decision to adjust price as well as the size of the price adjustment may reflect the deviation from the long run equilibrium relation. ${ }^{18}$

In the ordered probit regression $\Delta_{+} M C, \Delta M C, \Delta_{+} M C_{-l}$, and $\Delta M C_{-1}$ are all individually significant and point estimates for the lagged variables are considerably

\footnotetext{
$18 \hat{u}$ is an estimated variable and thus our parameter estimates will be inefficient.
} 
lower. Even though inclusion of $\Delta M C_{-I}$ leads to lower point estimates of $\triangle M C$, the total effect of changes in marginal cost is larger than those in the second and third columns. We can not reject, at the $10 \%$ level, that $\Delta_{+} M C$ equals $\triangle M C$ and $\Delta_{+} M C_{-I}$ equals $\Delta M C_{-I}$. This is another indication that there are no apparent asymmetric effects from upward and downward movements in the marginal cost. The negative and significant $\hat{u}$ shows that when the current price is above the long run equilibrium price it is less (more) likely that the price is increased (decreased). In the OLS regressions the coefficient of $\hat{u}$ is about -0.1 and significant for both price increases and decreases which suggests that when the price is at a relatively high level the price increases (decreases) are relatively smaller (larger). The level of significance of the OLS coefficients in the regression with price decreases is low due to the low variation in $\lambda$.

The decomposition of $\triangle M C$ and $\triangle M C_{-1}$ is of minor importance to the results. We note that it is possible to reject that $\Delta E^{*} S P(-1)$ and $\Delta S P^{*} E(-1)$ have the same effect in the ordered probit regression (at the $10 \%$ level). It can also be rejected, in both the ordered probit and OLS regression for price increases, that $\Delta E^{*} S P(-1)+$ $\left(\Delta E^{*} S P(-1)\right)_{-1}$ and $\Delta S P^{*} E(-1)+\left(\Delta S P^{*} E(-1)\right)_{-1}$ are equal. This is an indication that not only do changes in the exchange rate have a more rapid effect than changes in the spot market price on the decision to adjust price, but also that price increases are more sensitive to changes in the former. ${ }^{19}$

To sum up the results of this section we find that, as expected, the price is more likely to be adjusted when there has been large movement(s) in the underlying cost variable(s). However, it appears as if the cost changes can be quite large without causing any price adjustment. Lagged independent variables are significant such that price adjustments reflect past changes in cost variables. The only asymmetry in response to cost changes is that it is more likely that price is adjusted when there has been a change in the exchange rate than in the spot market price. When we estimated the size of the change we found quite low point estimates (about 0.2-0.3) of $\triangle M C$. One striking feature is that the explanatory power of the regression for the size of price decreases is quite low, suggesting that in the short run it is difficult to predict exactly how large a decrease will be.

\footnotetext{
${ }^{19}$ See Table A1 in Appendix 2 which summarizes the tests of symmetries in the behavior of prices in response to different cost changes.
} 


\subsection{Monthly frequency}

Even though we introduced lagged independent variables and a measure of the deviation from the long run equilibrium relation in section 4.1, we did so in quite an arbitrary fashion. The standard procedure for studying dynamic adjustment is to employ an error correction framework, which is pursued in this section. Instead of using changes in the cost variables since the last price adjustment we now look at cost and price changes at a monthly basis. Since the price is almost never unchanged for more than a month this reduces the problem that the dependent variable is zero for the majority of observations as is the case with data of daily and weekly frequency. In our theoretical discussion we pointed out that quadratic adjustment costs cause a gradual movement towards the equilibrium level. That is, the price is not adjusted all the way to its equilibrium level once it does adjust. Partial adjustment implies that an error correction model may be a better description of our data - there remains an "error" from the last adjustment. ${ }^{20}$

The first step in an error correction approach is to estimate the relationship in levels between price and the explanatory variables. This long-run equilibrium relation was reported in equation (5). In the short run the price may deviate from the long-run equilibrium level because of stochastic shocks and adjustment costs. The estimated error term $\hat{u}$ may be interpreted as the deviation from long run equilibrium. For all specifications reported in tables 7 and 8 Engle-Granger tests reject that $\hat{u}$ has a unit root so that (5) represents a cointegrating relationship. The second step is estimation of the error correction form

$$
\Delta R P_{t}=\alpha_{0}+\alpha_{1} \hat{u}_{t-1}+\alpha_{2} \Delta \mathbf{X}_{t}+\alpha_{3} \Delta \mathbf{X}_{t-1}+\alpha_{4} \Delta \mathbf{X}_{t-2}+v_{t},
$$

\footnotetext{
${ }^{20}$ Kasa (1992) is one example of earlier work that applies an error correction model to (quantity) adjustment when there are exchange rate shocks.
} 
where it is assumed that two lags of the independent variables are sufficient to capture the dynamics. ${ }^{21} \alpha_{1}$ is the estimate of how much of the misadjustment (relative to longrun equilibrium) in the previous period that is corrected in this period.

\section{Table 7 about here}

We see from Table 7 that the parameter estimates are stable across specifications. Overall, contemporaneous explanatory variables are significant at the 1 percent level whereas lagged variables have varying significance levels. First we focus on the estimation reported in column (1). A change in marginal costs of one unit on average leads to a price adjustment of 0.54 in that same month (which is similar to the point estimate in the naïve (6)). The important fact to note is that not all adjustment takes place in the same month. The price change on average reflects 0.18 of the previous month's change in marginal cost. Further, the estimated coefficient for $\hat{u}$ indicates that about -0.27 of the misadjusted price from the previous month is corrected in this month. The estimates reported in Table 7 confirm the findings in the preceding section that tax-changes are immediately passed through to prices (coefficient of 0.74) since lagged values have low point estimates and are not statistically significant. $\triangle W A G E$ shows much less variation than the other variables and is highly correlated with the consumer price index. A change of one unit in the nominal wage index implies a nominal price change of about unity. We postpone further discussion of the pass-through pattern of $T A X, E$ and $S P$ until further below.

The regression reported in column (2) of Table 7 allows us to study if the responsiveness of price is symmetric in decreases and increases of the marginal cost. An increase in $M C$ of one unit results in a contemporaneous price increase of about 0.7. There is no statistically significant effect of previous month's increases in $M C$ on the price change. A decrease in $M C$ of one unit, on the other hand, results in a contemporaneous price decrease of only 0.35 . However, there is a statistically significant effect of the previous months decrease in $M C$ on the price change of about 0.31. Taken together this means that the price responded more rapidly to cost increases than to decreases, but that the long-run pass-through is symmetric for

${ }^{21}$ In preliminary regressions we experimented with longer lags of the independent variables as well 
increases and decreases. The accumulated pass-through after two months is slightly lower than 0.7 for both price increases and price decreases. It is not possible to reject at any reasonable level that the long run pass-through of $\triangle M C$ and $\triangle T A X$ is equal.

Despite the differences in market structure we thus find a similar pattern in our Swedish data as previously have been found on British and U.S. data. Using semiweekly survey data for the period 1986-1992 Borenstein et al. (1997) find that retail gasoline prices in the United States responded more rapidly to cost increases than to cost decreases. ${ }^{22}$ Bacon (1991) uses British retail prices (fortnightly data) for the period 1982-1989 and the Rotterdam spot market price as cost. Bacon also found that retail gasoline prices responded more rapidly to increases in costs than to decreases. Kirchgässner and Kübler (1992) on the other hand, using monthly data, find that for the German gasoline market retail price adjustment has been rapid, symmetric and full to Rotterdam spot price changes during 1980-1989 (but asymmetric for 1972-1979).

Another question related to symmetry is if price is equally responsive to changes in different explanatory variables. Table 8 below presents the results of an error correction specification when $M C$ has been separated into $E$ and $S P$.

Table 8 about here

Comparing Table 8 with Table 7 we see that the point estimates of $\hat{u}, \Delta T A X$ and $\triangle W A G E$ are essentially unchanged. There are now some more restrictions to be tested. From the results of column (1) we can reject, at the $10 \%$ level, that the longrun pass-through of $\triangle T A X$ and $\triangle S P$ and $\Delta E$ are equal. Long run pass-through of these variables is about 0.6-0.7. The timing of pass-through is somewhat different for the different explanatory variables. For $T A X$ and $E$ more of the adjustment takes place in the same month compared to $S P$.

Further insights may be gained by separating changes into increases and decreases in $E$ and $S P$ respectively. This is done in column (2). For $S P$ increases we

as lagged $\triangle R P$. However their coefficients were always small and statistically insignificant.

22 There is much more vertical differentiation in the U.S. gasoline market(s) than in the Swedish (see section 3). Borenstein et al. (1997) study price responses at various levels in the distribution chain; crude oil, spot market gasoline price, local wholesale price ("terminal") and retail price. As discussed in section 3 the relevant input price for the retail pricing decision in the Swedish gasoline market is the spot price of gasoline in Rotterdam (converted into Swedish kronor). 
see that they are passed through in the same month as they occur (point estimate of about 0.62 ), whereas price adjustment to $S P$ decreases is about the same but is spread out over two months (pass-through of about 0.3 in the same month and of about 0.28 from the previous month). Similarly the adjustment to $E$ changes takes place fully in the same month as changes occur. Also in the case of $E$ the price response to increases (0.94) is significantly larger than the response to decreases $(0.74)$. One study to compare with is Feenstra (1989) who tests if the long-run pass-through of tariffs and exchange rates (onto prices of Japanese cars, trucks and motorcycles in the U.S. market) are equal. He does not reject the hypotheses that pass-through is symmetric, that a tariff change is passed through to the same extent as a exchange rate change. ${ }^{23}$

We experimented with specifications where all variables were deflated by consumer price index. Column (3) in Table 7 below reports one of those regressions. The estimated parameters (except for the constant) are roughly the same as for the nominal regressions where $W A G E$ was included as explanatory variable. ${ }^{24}$

Summing up Section 4.2 we have found the following results about price adjustment; the timing of pass-through is asymmetric in the sense that increases in $M C$ and $S P$ are passed through more rapidly onto retail prices than decreases. Pass-through is also asymmetric in the sense that the coefficients of contemporaneous $T A X$ and $E$ changes are larger than for SP changes. This implies that the stochastic structure and other characteristics of a variable affect its short run effect on price. TAX is nonstochastic as opposed to $E$ and $S P$, the later two both follow random walks. The long run pass-through is largely symmetric and reached in as short a period as two months.

\footnotetext{
23 Again we refer to Table A1 in appendix 2 which summarizes the tests of symmetries in the behavior of prices in response to different cost changes.

${ }^{24}$ WAGE was not included in the CPI deflated regressions since it is highly correlated with CPI.
} 


\section{Concluding remarks}

Economists' interest in price rigidities is primarily motivated by their implications for macro-economic adjustment and transmission of cost and demand shocks. Price on the Swedish gasoline market is flexible enough for us to expect that the price rigidity on this market is of limited macro-economic consequence. This said, we believe that the high quality of our data allow us to go further than the existing empirical literature on price adjustment. Having access to daily input and retail prices for a firm over a prolonged period allows us to test implications of different theories for how prices are set when there are costs associated with adjustment. One can distinguish between three main theories for how prices are set when there are costs of adjustment; statedependent pricing with fixed adjustment costs (Ss), time-dependent pricing, and partial adjustment. Below we summarize the contribution that each one of these theories make to our understanding of price adjustment on the Swedish gasoline market.

At a first glance the Swedish gasoline industry seems to offer a text-book example of state-dependent pricing in its simplest form. Even though input prices move virtually every day we observe infrequent price adjustment (on average every third week) and no small price changes. In section 4.1 we found that price adjustment is more likely to take place the further input costs have drifted since the last adjustment. The price adjustment to tax changes is also consistent with fixed (or zero) adjustment costs, adjustment appears to take place immediately and almost fully. These are three observations consistent with fixed adjustment costs.

However, there are some features of our data that are not explained by only fixed adjustment costs. The most obvious inconsistency (not only with the fixed adjustment cost hypothesis!) is that there are a number of cases when the price is increased (decreased) despite the fact that cost has decreased (increased). Another feature left unexplained is that there are extended periods when price is well above the long run equilibrium level and that prices are not adjusted to this level when they are set. Even more striking is the fact that lagged independent variables have explanatory power in section 4.1, which would not be the case if prices were always adjusted back to the static optimum.

We study the timing of the price changes and find only very limited evidence of time-dependent pricing, that is of price adjustment taking place at a specific point in 
time (e.g. "prices are set on the first day each month"). This conclusion is based on an investigation of the time lapsed between price adjustments where we find some support for prices being adjusted with seven day intervals. We do not find any evidence that prices are adjusted on a specific day of the week. ${ }^{25}$ As discussed by Blanchard and Fischer (1989, p 413) time dependent price setting rules are likely to be most relevant when it is costly to learn about the state and when one wants to economize on information collection. The most important factors for price setting in the gasoline market are all readily observable by the firms. The lack of evidence supporting timedependent pricing is therefore not surprising.

The lagged independent variables were significant and important when we estimated the size of price adjustments. In addition we found that there is a very strong relationship between prices and cost in the long run. These two features of the data lead us to use a relatively free econometric specification of the development of prices. More specifically, we followed a number of recent articles by applying an error correction model. The general motivation for the inclusion of lagged variables and deviation from the long run equilibrium is that there are quadratic costs of adjusting the price. Our results are in line with previous studies of gasoline prices, adjustments depend on both current and lagged independent variables and prices are adjusted towards the long run equilibrium. However, motivating the model with quadratic adjustment costs is inconsistent with what we find for the tax changes. This corresponds to the largest cost changes, and one would therefore expect the adjustment process to take more time than for the relatively small cost changes caused by exchange rate and spot market movements. We find the opposite.

No single theory is consistent with all features of price adjustments. This may in itself not be surprising since there are specificities of single price adjustment that are unobservable to the researcher. Good examples of such unobservables are the beliefs (being rational or not) of the firm regarding the future development of costs, responses of competitors, and consumers' reactions to price adjustments. Referring back to Figure 1 in the introduction, inferences on price setting behavior will be highly dependent on the data analyzed. For example, if one only had access to the price series

\footnotetext{
25 We do find that price adjustment is unlikely to take place on weekends and Mondays. This is probably related to the input market being closed on Saturday and Sunday and difficulties to
} 
(or only the distribution of price adjustments) it would be easy to conclude that the Ssmodel is an accurate description of price setting. On the other hand, if data were sampled only at (longer) discrete intervals the conclusion could instead be in favor of the partial adjustment model. Thus proponents of almost any theory could find support for their beliefs.

This may seem like a negative conclusion to be drawn after going through all the statistics of the paper. However, considering the complexity of real world behavior it is comforting to note that within a relatively short time prices revert back to some long run equilibrium level. A reflection of this is that the ultimate price adjustment is symmetric, both for price increases and decreases as well as for different costs (tax). There is evidence of asymmetries in the price adjustment process in the short run however. In the short run we could say that prices are sticky downwards since the full adjustment is slower for cost decreases than for increases. However, for the Swedish gasoline market the short run is only a few months. 


\section{References}

Awh, Robert Y. and Walter J. Primeaux, Jr., 1992, A more general theory of kinked demand curve: Theory and empirical test, Quarterly Review of Economics and Finance, 32:99-117.

Bacon, Robert W., 1991, Rockets and feathers: the asymmetric speed of adjustment of UK retail gasoline prices to cost changes, Energy Economics, 211- 218.

Barro, Robert, 1972, A theory of monopolistic price adjustment, Review of Economic Studies, 34, 17-26.

Blanchard, Oliver J. and Stanley Fisher, 1989, Lectures on Macroeconomics, The MIT Press, Cambridge, MA.

Blinder, Alan S., 1991, Why are prices sticky? Preliminary results from an interview study, American Economic Review Papers and Proceedings, 81:89-100.

Borenstein, Severin, A. and Andrea Shephard, 1996, Dynamic pricing in retail gasoline markets, RAND Journal of Economics, 27:429-51.

Borenstein, Severin, A. Colin Cameron and Richard Gilbert, 1997, Do gasoline prices respond asymmetrically to crude oil price changes?, The Quarterly Journal of Economics, 112: 305-339.

Carlton, Dennis W., 1986, The rigidity of prices, American Economic Review, 76:637658.

Carlton, Dennis W., 1989, The theory and the fact of how markets clear: Is industrial organization valuable for understanding macroeconomics?, In Handbook of industrial organization, edited by R.Schmalensee and R.D. Willig, Elsevier Science Publishers, B.V. 
Cecchetti, Stephen G., 1986, The frequency of price adjustment: A study of the newsstand prices of magazines, Journal of Econometrics, 31: 255-274.

Dahlby, Bev, 1992, Price adjustment in an automobile insurance market: A test of the Sheshinski-Weiss model, Canadian Journal of Economics, 564-583.

Dixit, Avinash and Robert Pindyck, 1994, Investment under Uncertainty, Princeton University Press, Princton, NJ.

Domberger, Simon, and Denzil G.Fiebig, 1993, The distribution of price changes in oligopoly, Journal of Industrial Economics, 41:295-313.

Duffy-Deno, Kevin T., 1996, Retail price asymmetries in local gasoline markets, Energy Economics 18: 81-92.

Ellison, Glenn, 1994, Theories of cartel stability and the joint executive commitee, RAND Journal of Economics, 25, 37-57.

Feenstra, Robert., 1989, Symmetric pass-through of tariffs and exchange rates under imperfect competition: an empirical test, Journal of International Economics, 27: 2545.

Feenstra, Robert, Gagnon, Joseph and Michael Knetter, 1996, Market share and exchange rate pass-through in world automobile trade, Journal of International Economics, 40:187-207.

Gagnon, Joseph E. and Michael Knetter M, 1995, Markup adjustment and exchange rate fluctuations: Evidence from panel data on automobile exports, Journal of International Money and Finance, 14:289-310.

Goldberg, Penelopi K., 1995, Product differentiation and oligopoly in international markets: the case of the U.S. automobile industry, Econometrica, 63:891-951. 
Gujarati, Damodar, 1995, Basic Econometrics, third edition, Mc Graw-Hill, New York.

Heckman, J.,1979, Sample selection bias as a specification error, Ecomometrica, 47: 153-161.

Kasa, K., 1992, Adjustment costs and pricing-to-market, theory and evidence, Journal of International Economics, 32:1-30.

Kashyap, Anil K., 1995, Sticky prices: New evidence from retail catalogs, Quarterly Journal of Economics, 110:245-274.

Kirchgässner, Gebhard and Knut Kübler, 1992, Symmetric or asymmetric price adjustment in the oil market, Energy Economics,171-185.

Kraft, Kornelius, 1995, Determinants of price adjustment, Applied Economics, 27:501507.

Lach, Saul, and Daniel Tsiddon, 1996, Staggering and synchronization in price setting: Evidence from multiproduct firms, American Economic Review, 86:1175-1196.

Mankiw, N.G, and D.Romer, 1991, New Keynesian economics Vol 1. Imperfect competition and sticky prices, Cambridge Mass. and London, MIT Press.

Menon, Jayant, 1995, Exchange rate pass-through, Journal of Economic Surveys, 9:197-231.

Neumark, David and Steven A.Sharpe, 1992, Market structure and the nature of price rigidity: Evidence from the market for consumer deposits, Quarterly Journal of Economics, 107:657-680. 
Slade, Margaret E., 1995, Product rivalry with multiple strategic weapons: An analysis of price and advertising competition, Journal of Economics and Management Strategy, 4:445-476.

Slade, Margaret E., 1992, Vancover's gasoline-price wars: An empirical exercise in uncovering supergame strategies, Review of Economic Studies, 59:257-76.

Slade, Margaret E., 1991, Market structure, marketing method, and price instability, Quarterly Journal of Economics, 106:1309-1340.

Swedish Petroleum Institute, Annual Reports 1980-1996.

Weiss, C., 1993, Price inertia and market structure: Empirical evidence from Austrian manufacturing, Applied Economics, 25:1175-1186. 
Table 1. Variable definitions and data sources.

\begin{tabular}{|c|c|}
\hline VARIABLE & DEFINITION AND DATA SOURCE \\
\hline$R P$ & $\begin{array}{l}\text { Retail list price for premium leaded gasoline for one of the firms, namely Shell. The } \\
\text { retail price is at 0-zone, i.e. where the transport cost is the lowest. VAT is excluded } \\
\text { from the price according to the formula: } R P=\text { consumer price/ }(1+V A T) \text { measured in } \\
\text { SEK*100/litre. Source: Shell. }\end{array}$ \\
\hline$S P$ & $\begin{array}{l}\text { The spot market price of premium leaded gasoline. From November } 1985 \text { to } \\
\text { December } 1996 \text { it is the average of high (from refinery) and low (stored or blended } \\
\text { material) daily quotations, FOB Rotterdam for Premium } 0.15 \mathrm{~g} / \mathrm{l} \text {. Size is barges } \\
(1,000-5,000 \mathrm{mt} \text { ) and delivery is North West Europe. Prices are assessed daily up } \\
\text { until } 1830 \mathrm{GMT} \text {. For the period January } 1980 \text { to October } 1985 \text { it is for } \\
\text { Mediterranean/Italian delivery of regular gasoline plus USD } 24 \text {, which was the } \\
\text { average difference between the two prices for the period where we have access to } \\
\text { both. The FOB price is transformed from USD/mt to USD/liter by the factor } \\
8.35 * 159 . \mathrm{SP} \text { is measured in USD*100/litre. Source: Platt's, London. }\end{array}$ \\
\hline$E$ & $\begin{array}{l}\text { The exchange rate between Swedish kronor and US dollars. Source: Findata (January } \\
1983 \text { to December 1996), Stefan Nydahl, Uppsala University (January } 1980 \text { to } \\
\text { December 1982). }\end{array}$ \\
\hline$M C$ & $\begin{array}{l}\text { Spot market price of premium leaded gasoline measured in } \mathrm{SEK}^{*} 100 / \text { litre. } \mathrm{MC} \text { is } \\
\text { obtained by the formula: } M C=S P^{*} E\end{array}$ \\
\hline$C P I$ & Consumer price index. Source: International Financial Statistics. \\
\hline$W A G E$ & $\begin{array}{l}\text { Index of nominal hourly wages in the manufacturing sector (SNI 3). Source: } \\
\text { International Financial Statistics, heading } 14465 . \mathrm{ff}\end{array}$ \\
\hline$D A Y S F I X E D$ & The number of days the price has been fixed since latest price adjustment. \\
\hline$T A X$ & $\begin{array}{l}\text { Total tax per liter premium leaded gasoline. Source: The Swedish Petroleum } \\
\text { Institute, Annual report } 1995 .\end{array}$ \\
\hline$\Delta_{\text {sgn }} X_{\text {lag }}$ & $\begin{array}{l}\text { Changes in the variable } X \text { is denoted } \Delta X \text {. In Section } 2 \text { and Section } 4.1 \Delta \text { refers to the } \\
\text { change since the last price adjustment and in Section } 4.2 \text { it refers to the change since } \\
\text { last month. The sign of the changes is displayed in the subscript on } \Delta . \text { The subscript } \\
\text { on } X \text { denotes the number of lags. } \\
\text { One example: In Section } 4.2 \Delta_{+} M C_{-2}=M C_{-2}-M C_{-3} \text { conditional on it being positive }\end{array}$ \\
\hline$\Delta S P^{*} E(-1)$ & Change in $S P$ holding the value of $E$ fixed. \\
\hline$\Delta E * S P(-1)$ & Change in $E$ holding the value of $S P$ fixed. \\
\hline$\left(\Delta S P^{*} E(-1)\right)_{-1}$ & One period lag of the change in $S P$ holding the value of $E$ fixed. \\
\hline$\left(\Delta E^{*} S P(-1)\right)_{-1}$ & One period lag of the change in $E$ holding the value of $S P$ fixed. \\
\hline$V A T$ & $\begin{array}{l}\text { Value added tax. Calculated on producer price including TAX. A VAT of } 23.46 \% \text { was } \\
\text { levied on gasoline on March 1, 1990, it was subsequently (July 1, 1991) increased to } \\
25.00 \% \text {. Source: The Swedish Petroleum Institute, Annual report 1995. }\end{array}$ \\
\hline
\end{tabular}


Table 2: Descriptive statistics for all price adjustments.

\begin{tabular}{l|llllllll}
\hline & Mean & Std.Dev & Skew & Kurt & Min & Max & Median & Cases \\
\hline$\Delta \boldsymbol{R P} \neq \mathbf{0}$ & & & & & & & & \\
$\Delta R P$ & 1.55 & 11.05 & 3.0 & 23.7 & -16.20 & 95.20 & 3.20 & 250 \\
$\Delta M C$ & 0.04 & 9.26 & 0.3 & 6.0 & -37.26 & 35.54 & -0.27 & 250 \\
$\Delta S P^{*} E(-1)$ & -0.31 & 8.84 & 0.4 & 6.2 & -35.09 & 35.42 & 0.00 & 250 \\
$\Delta E^{*} S P(-1)$ & 0.37 & 3.94 & 1.4 & 15.2 & -14.27 & 26.24 & 0.12 & 250 \\
$D A Y S F I X E D$ & 21.59 & 23.90 & 2.6 & 12.4 & 0 & 177 & 13 & 250 \\
$\Delta \boldsymbol{R P}>\mathbf{0}$ & & & & & & & & \\
$\Delta R P$ & 9.09 & 10.22 & 5.4 & 41.8 & 2.00 & 95.20 & 6.00 & 130 \\
$\Delta M C$ & 4.62 & 8.69 & 0.9 & 5.3 & -17.00 & 35.54 & 3.98 & 130 \\
$\Delta S P^{*} E(-1)$ & 3.11 & 8.37 & 0.9 & 5.5 & -17.64 & 35.42 & 1.79 & 130 \\
$\Delta E^{*} S P(-1)$ & 1.54 & 4.46 & 1.4 & 14.0 & -14.27 & 29.24 & 0.70 & 130 \\
$D A Y S F I X E D$ & 24.81 & 26.64 & 2.6 & 12.3 & 1 & 177 & 14 & 130 \\
$\Delta \boldsymbol{R} \boldsymbol{P}<\boldsymbol{0}$ & & & & & & & & \\
$\Delta R P$ & -6.62 & 3.59 & -1.4 & 3.9 & -16.20 & -2.00 & -5.60 & 120 \\
$\Delta M C$ & -4.92 & 7.05 & -1.2 & 8.5 & -37.26 & 21.14 & -3.55 & 120 \\
$\Delta S P^{*} E(-1)$ & -4.02 & 7.38 & -0.8 & 7.1 & -35.09 & 24.02 & -2.78 & 120 \\
$\Delta E^{*} S P(-1)$ & -0.89 & 2.65 & -0.5 & 4.4 & -9.77 & 5.33 & -0.68 & 120 \\
$D A Y S F I X E D$ & 18.10 & 20.06 & 2.2 & 7.8 & 0 & 104 & 11 & 120 \\
\hline
\end{tabular}


Table 3: Descriptive statistics for the sub periods 1980-84, 1985-89, and 1990-96.

(Standard deviations in parenthesis.)

\begin{tabular}{|c|c|c|c|c|c|c|c|}
\hline & $\begin{array}{l}|\Delta R P| \\
\text { Mean }\end{array}$ & $\begin{array}{l}|\Delta M C| \\
\text { Mean }\end{array}$ & $\begin{array}{c}\Delta S P^{*} E(-1) \\
\text { Mean }\end{array}$ & $\begin{array}{c}\Delta S P^{*} E(-1) \\
\text { Mean }\end{array}$ & $\begin{array}{c}\text { DAYSFIXED } \\
\text { Mean }\end{array}$ & $\begin{array}{c}\text { Nobs. } \\
\Delta R P>0\end{array}$ & $\begin{array}{c}\text { Nobs. } \\
\Delta R P<0\end{array}$ \\
\hline $1980-1984$ & $\begin{array}{c}8.89 \\
(8.54)\end{array}$ & $\begin{array}{c}7.61 \\
(7.33)\end{array}$ & $\begin{array}{c}7.10 \\
(6.61)\end{array}$ & $\begin{array}{c}4.08 \\
(4.79)\end{array}$ & $\begin{array}{c}38.18 \\
(27.49)\end{array}$ & 28 & 16 \\
\hline $1985-1989$ & $\begin{array}{c}9.45 \\
(5.13)\end{array}$ & $\begin{array}{c}9.06 \\
(7.57)\end{array}$ & $\begin{array}{c}8.63 \\
(7.99)\end{array}$ & $\begin{array}{c}3.30 \\
(3.30)\end{array}$ & $\begin{array}{c}31.84 \\
(36.30)\end{array}$ & 20 & 24 \\
\hline $1990-1996$ & $\begin{array}{c}7.22 \\
(8.23)\end{array}$ & $\begin{array}{c}5.53 \\
(5.81)\end{array}$ & $\begin{array}{c}4.93 \\
(5.81)\end{array}$ & $\begin{array}{c}1.88 \\
(2.05)\end{array}$ & $\begin{array}{c}14.30 \\
(13.13)\end{array}$ & 82 & 80 \\
\hline $1980-1996$ & $\begin{array}{r}7.90 \\
(7.86) \\
\end{array}$ & $\begin{array}{r}6.52 \\
(6.56) \\
\end{array}$ & $\begin{array}{r}5.96 \\
(6.52) \\
\end{array}$ & $\begin{array}{c}2.52 \\
(3.06) \\
\end{array}$ & $\begin{array}{c}21.59 \\
(23.90) \\
\end{array}$ & 130 & 120 \\
\hline
\end{tabular}

Table 4: Number of price adjustments over the year and week.

\begin{tabular}{l|llllllllllll}
\hline & Jan & Feb & Mar & Apr & May & Jun & Jul & Aug & Sep & Oct & Nov & Dec \\
\hline $\begin{array}{l}\text { Quantity } \\
1000 m^{3}\end{array}$ & 370 & 386 & 438 & 446 & 465 & 497 & 526 & 501 & 450 & 448 & 422 & 433 \\
$\Delta R P>0$ & 12 & 13 & 10 & 17 & 5 & 13 & 9 & 12 & 11 & 10 & 7 & 11 \\
$\Delta R P<0$ & 9 & 6 & 9 & 6 & 7 & 11 & 10 & 10 & 13 & 14 & 11 & 14 \\
& Mon & Tue & Wed & Thu & Fri & Sat & Sun & & & & & \\
$\Delta R P>0$ & 9 & 31 & 33 & 29 & 18 & 5 & 5 & & & & & \\
$\Delta R P<0$ & 13 & 34 & 25 & 20 & 20 & 8 & 0 & & & & & \\
\hline
\end{tabular}


Table 5. Ordered probit and OLS estimates. MC. Daily frequency.

\begin{tabular}{|c|c|c|c|c|c|c|}
\hline & $\begin{array}{l}\text { (1) Ordered } \\
\text { Probit }\end{array}$ & (2) $O L S$ & (3) $O L S$ & $\begin{array}{l}\text { (4) Ordered } \\
\text { Probit }\end{array}$ & (5) $O L S$ & (6) $O L S$ \\
\hline VARIABLE & $\mathrm{Z}$ & $\Delta \mathrm{RP} \mid \Delta \mathrm{RP}>0$ & $\Delta \mathrm{RP} \mid \Delta \mathrm{RP}<0$ & $\mathrm{Z}$ & $\Delta \mathrm{RP} \mid \Delta \mathrm{RP}>0$ & $\Delta \mathrm{RP} \mid \Delta \mathrm{RP}<0$ \\
\hline CONSTANT & $\begin{array}{l}2.13^{* * * *} \\
(0.0426)\end{array}$ & $\begin{array}{l}2.42 \\
(1.61)\end{array}$ & $\begin{array}{l}3.93 \\
(10.9)\end{array}$ & $\begin{array}{l}2.14 * * * \\
(0.0549)\end{array}$ & $\begin{array}{l}3.86 * * * \\
(1.38)\end{array}$ & $\begin{array}{l}5.93 \\
(13.0)\end{array}$ \\
\hline$\Delta M C$ & $\begin{array}{l}0.0686 * * * \\
(0.00737)\end{array}$ & $\begin{array}{l}0.283 * * * \\
(0.0469)\end{array}$ & $\begin{array}{l}0.275 * \\
(0.148)\end{array}$ & & $\begin{array}{l}0.217 * * * \\
(0.0496)\end{array}$ & $\begin{array}{l}0.186 \\
(0.169)\end{array}$ \\
\hline$\Delta_{+} M C$ & & & & $\begin{array}{l}0.0639 * * * \\
(0.00905)\end{array}$ & & \\
\hline$\triangle M C$ & & & & $\begin{array}{l}0.0575 * * * \\
(0.00906)\end{array}$ & & \\
\hline$\Delta M C_{-l}$ & & & & & $\begin{array}{l}0.141 * * * \\
(0.0405)\end{array}$ & $\begin{array}{l}0.133 \\
(0.105))\end{array}$ \\
\hline$\Delta_{+} M C_{-I}$ & & & & $\begin{array}{l}0.0111 * \\
(0.00567)\end{array}$ & & \\
\hline$\Delta M C_{-I}$ & & & & $\begin{array}{l}0.0115^{*} \\
(0.00670)\end{array}$ & & \\
\hline$(\Delta M C)^{2}$ & $\begin{array}{l}-0.00167 * * * \\
(3.03 \mathrm{E}-4)\end{array}$ & & & $\begin{array}{l}-0.00152 * \\
(3.10 \mathrm{E}-4)\end{array}$ & & \\
\hline$\hat{u}$ & & & & $\begin{array}{l}-0.00876 * * * \\
(0.00293)\end{array}$ & $\begin{array}{l}-0.0942 * * * \\
(0.0366)\end{array}$ & $\begin{array}{l}-0.147 * * \\
(0.0664)\end{array}$ \\
\hline$D T A X$ & $\begin{array}{l}3.63 * * * \\
(0.413)\end{array}$ & & & $\begin{array}{l}3.73 * * * \\
(0.425)\end{array}$ & & \\
\hline$\triangle T A X$ & & $\begin{array}{l}0.851 * * * \\
(0.0410)\end{array}$ & & & $\begin{array}{l}0.820 * * * \\
(0.0359)\end{array}$ & \\
\hline MY1 & $\begin{array}{l}4.27 * * * \\
(0.0632)\end{array}$ & & & $\begin{array}{l}4.31 * * * \\
(0.0675)\end{array}$ & & \\
\hline Lambda & & $\begin{array}{l}1.59 * * \\
(0.701)\end{array}$ & $\begin{array}{l}4.02 \\
(4.48)\end{array}$ & & $\begin{array}{l}0.744 \\
(0.604)\end{array}$ & $\begin{array}{l}4.53 \\
(5.33)\end{array}$ \\
\hline $\operatorname{AdjR2}$ & & 0.838 & 0.112 & & 0.860 & 0.317 \\
\hline$D-W$ & & 1.59 & 1.14 & & 1.57 & 1.41 \\
\hline $\log L$ & -1090.4 & & & -1067.1 & & \\
\hline$N O B S$ & 5693 & 130 & 120 & 5595 & 129 & 120 \\
\hline
\end{tabular}


Table 6. Ordered probit and OLS estimates. SP and E. Daily frequency.

\begin{tabular}{|c|c|c|c|c|c|c|}
\hline & $\begin{array}{l}\text { (1) Ordered } \\
\text { Probit }\end{array}$ & (2) $O L S$ & (3) $O L S$ & $\begin{array}{l}\text { (4) Ordered } \\
\text { Probit }\end{array}$ & (5) $O L S$ & (6) $O L S$ \\
\hline VARIABLE & $\mathrm{Z}$ & $\Delta \mathrm{RP} \mid \Delta \mathrm{RP}>0$ & $\Delta \mathrm{RP} \mid \Delta \mathrm{RP}<0$ & $\mathrm{Z}$ & $\Delta \mathrm{RP} \mid \Delta \mathrm{RP}>0$ & $\Delta \mathrm{RP} \mid \Delta \mathrm{RP}<0$ \\
\hline CONSTANT & $\begin{array}{l}2.13 * * * \\
(0.0433)\end{array}$ & $\begin{array}{l}1.59 \\
(1.66))\end{array}$ & $\begin{array}{l}2.72 \\
(15.2)\end{array}$ & $\begin{array}{l}2.16^{* * * *} \\
(0.0455)\end{array}$ & $\begin{array}{l}3.13 * * \\
(1.40)\end{array}$ & $\begin{array}{l}9.39 \\
(28.3)\end{array}$ \\
\hline$\Delta S P^{*} E(-1)$ & $\begin{array}{l}0.0564 * * * \\
(0.00810)\end{array}$ & $\begin{array}{l}0.272 * * * \\
(0.0496)\end{array}$ & $\begin{array}{l}0.226 \\
(0.177)\end{array}$ & $\begin{array}{l}0.0467 * * * \\
(0.00848)\end{array}$ & $\begin{array}{l}0.203 * * * \\
(0.0517)\end{array}$ & $\begin{array}{l}0.210 \\
(0.287)\end{array}$ \\
\hline$\left(\Delta S P^{*} E(-1)\right)_{-1}$ & & & & $\begin{array}{l}0.0132 * * * \\
(0.00390)\end{array}$ & $\begin{array}{l}0.127 * * * \\
(0.0443)\end{array}$ & $\begin{array}{l}0.149 \\
(0.187)\end{array}$ \\
\hline$\Delta E^{*} S P(-1)$ & $\begin{array}{l}0.0747 * * * \\
(0.0130)\end{array}$ & $\begin{array}{l}0.415 * * * \\
(0.0955)\end{array}$ & $\begin{array}{l}0.260 \\
(0.356)\end{array}$ & $\begin{array}{l}0.0773 * * * \\
(0.0134)\end{array}$ & $\begin{array}{l}0.329 * * * \\
(0.0848)\end{array}$ & $\begin{array}{l}0.323 \\
(0.669)\end{array}$ \\
\hline$\left(\Delta E^{*} S P(-1)\right)_{-1}$ & & & & $\begin{array}{l}0.00971 \\
(0.00695)\end{array}$ & $\begin{array}{l}0.190 * * \\
(0.0843)\end{array}$ & $\begin{array}{l}0.144 \\
(0.239)\end{array}$ \\
\hline$\left(\Delta S P^{*} E(-1)\right)^{2}$ & $\begin{array}{l}-0.00128 * * * \\
(3.48 \mathrm{E}-4)\end{array}$ & & & $\begin{array}{l}-0.00105 * * * \\
(3.61 \mathrm{E}-4)\end{array}$ & & \\
\hline$\left(\Delta E^{*} S P(-1)\right)^{2}$ & $\begin{array}{l}-0.00165 * * \\
(7.93 \mathrm{E}-4)\end{array}$ & & & $\begin{array}{l}-0.00183 * * \\
(8.44 \mathrm{E}-4)\end{array}$ & & \\
\hline$\hat{u}$ & & & & $\begin{array}{l}-0.0100 * * * \\
(0.00295)\end{array}$ & $\begin{array}{l}-0.101 * * * \\
(0.0378)\end{array}$ & $\begin{array}{l}-0.168 \\
(0.115)\end{array}$ \\
\hline$D T A X$ & $\begin{array}{l}3.61 * * * \\
(0.414)\end{array}$ & & & $\begin{array}{l}3.72 * * * \\
(0.425)\end{array}$ & & \\
\hline$\triangle T A X$ & & $\begin{array}{l}0.861 * * * \\
(0.0414)\end{array}$ & & & $\begin{array}{l}0.827 * * * \\
(0.0360)\end{array}$ & \\
\hline MY1 & $\begin{array}{l}4.26 * * * \\
(0.0660)\end{array}$ & & & $\begin{array}{l}4.31 * * * \\
(0.0700)\end{array}$ & & \\
\hline Lambda & & $\begin{array}{l}1.89 * * * \\
(0.724)\end{array}$ & $\begin{array}{l}3.53 \\
(6.21)\end{array}$ & & $\begin{array}{l}1.01 * \\
(0.614)\end{array}$ & $\begin{array}{l}5.87 \\
(11.4)\end{array}$ \\
\hline $\operatorname{AdjR} 2$ & & 0.844 & 0.100 & & 0.864 & 0.300 \\
\hline$D-W$ & & 1.51 & 1.10 & & 1.49 & 1.37 \\
\hline $\log L$ & -1090.9 & & & -1063.7 & & \\
\hline$N O B S$ & 5693 & 130 & 120 & 5595 & 129 & 120 \\
\hline
\end{tabular}


Table 7. Error correction model. Monthly frequency. Heteroskedacity consistent standard errors.

\begin{tabular}{|c|c|c|c|}
\hline & (1) $O L S$ & (2) $O L S$ & (3) $O L S$ \\
\hline VARIABLE & $\Delta \mathrm{RP}$ & $\Delta \mathrm{RP}$ & $\Delta \mathrm{RP} / \mathrm{CPI}$ \\
\hline CONSTANT & $\begin{array}{l}0.717 \\
(0.599)\end{array}$ & $\begin{array}{l}0.736 \\
(1.0050)\end{array}$ & $\begin{array}{l}0.003 \\
(0.0071)\end{array}$ \\
\hline$\hat{u}$ & $\begin{array}{l}-0.275^{* * *} * \\
(0.0523)\end{array}$ & $\begin{array}{l}-0.274 * * * \\
(0.0532)\end{array}$ & $\begin{array}{l}-0.221 * * * \\
(0.0470)\end{array}$ \\
\hline$\triangle T A X$ & $\begin{array}{l}0.745 * * * \\
(0.0515)\end{array}$ & $\begin{array}{l}0.750 * * * \\
(0.0512)\end{array}$ & $\begin{array}{l}0.741 * * * \\
(0.0684)\end{array}$ \\
\hline$\Delta T A X_{-1}$ & $\begin{array}{l}-0.0591 \\
(0.0525)\end{array}$ & $\begin{array}{l}-0.0586 \\
(0.0522)\end{array}$ & $\begin{array}{l}-0.0984 \\
(0.0699)\end{array}$ \\
\hline$\Delta W A G E$ & $\begin{array}{l}1.0186 * * * \\
(0.452)\end{array}$ & $\begin{array}{l}0.939 * * \\
(0.450)\end{array}$ & \\
\hline$\Delta M C$ & $\begin{array}{l}0.541 * * * \\
(0.0549)\end{array}$ & & $\begin{array}{l}0.430 * * * \\
(0.0554)\end{array}$ \\
\hline$\Delta M C_{-I}$ & $\begin{array}{l}0.183 * * * \\
(0.0586)\end{array}$ & & $\begin{array}{l}0.211^{* * *} \\
(0.0589)\end{array}$ \\
\hline$\Delta M C_{-2}$ & $\begin{array}{l}-0.0643 \\
(0.0551)\end{array}$ & & $\begin{array}{l}0.0148 \\
(0.0544)\end{array}$ \\
\hline$\Delta_{+} M C$ & & $\begin{array}{l}0.695 * * * \\
(0.0970)\end{array}$ & \\
\hline$\Delta_{+} M C_{-1}$ & & $\begin{array}{l}0.0289 \\
(0.103)\end{array}$ & \\
\hline$\Delta_{+} M C_{-2}$ & & $\begin{array}{l}-0.1003 \\
(0.104)\end{array}$ & \\
\hline$\triangle M C$ & & $\begin{array}{l}0.349 * * * \\
(0.103)\end{array}$ & \\
\hline$\Delta M C_{-1}$ & & $\begin{array}{l}0.311 * * * \\
(0.107)\end{array}$ & \\
\hline$\Delta M C_{-2}$ & & $\begin{array}{l}-0.0361 \\
(0.0978)\end{array}$ & \\
\hline$D-W$ & 1.96 & 1.97 & 2.05 \\
\hline Sum of squares & 9273.9 & 8962.4 & 1.5 \\
\hline Adj $R 2$ & 0.693 & 0.698 & 0.586 \\
\hline$N O B S$ & 178 & 178 & 178 \\
\hline
\end{tabular}

Variables starred with $* * *$ are significant at the $1 \%$ level, with $* *$ at the $5 \%$ level and with $*$ at the $10 \%$ level 
Table 8. Error correction model. Monthly frequency. Heteroskedacity consistent standard errors.

\begin{tabular}{|c|c|c|}
\hline & (1) $O L S$ & (2) $O L S$ \\
\hline VARIABLE & $\Delta R P$ & $\Delta R P$ \\
\hline CONSTANT & $\begin{array}{l}0.408 \\
(0.589)\end{array}$ & $\begin{array}{l}0.102 \\
(1.346)\end{array}$ \\
\hline$\hat{u}$ & $\begin{array}{l}-0.292 * * * \\
(0.0520)\end{array}$ & $\begin{array}{l}-0.288 * * * \\
(0.0538)\end{array}$ \\
\hline$\triangle T A X$ & $\begin{array}{l}0.726 * * * \\
(0.0520)\end{array}$ & $\begin{array}{l}0.723 * * * \\
(0.0523)\end{array}$ \\
\hline$\triangle T A X_{-I}$ & $\begin{array}{l}-0.0951 * \\
(0.0525)\end{array}$ & $\begin{array}{l}-0.0907 * \\
(0.0529)\end{array}$ \\
\hline$\triangle W A G E$ & $\begin{array}{l}1.0116 * * \\
(0.440)\end{array}$ & $\begin{array}{l}0.898 * * \\
(0.447)\end{array}$ \\
\hline$\Delta S P^{*} E(-1)$ & $\begin{array}{l}0.476 * * * \\
(0.0564)\end{array}$ & \\
\hline$\left(\Delta S P^{*} E(-1)\right)_{-1}$ & $\begin{array}{l}0.194 * * * \\
(0.0608)\end{array}$ & \\
\hline$\left(\Delta S P^{*} E(-1)\right)_{-2}$ & $\begin{array}{l}-0.112^{* *} \\
(0.0566)\end{array}$ & \\
\hline$\Delta E^{*} S P(-1)$ & $\begin{array}{l}0.850 * * * \\
(0.123)\end{array}$ & \\
\hline$\left(\Delta E^{*} S P(-1)\right)_{-1}$ & $\begin{array}{l}0.208 * \\
(0.124)\end{array}$ & \\
\hline$\left(\Delta E^{*} S P(-1)\right)_{-2}$ & $\begin{array}{l}0.166 \\
(0.126)\end{array}$ & \\
\hline$\Delta_{+} S P^{*} E(-1)$ & & $\begin{array}{l}0.624 * * * \\
(0.101)\end{array}$ \\
\hline$\left(\Delta_{+} S P^{*} E(-1)\right)_{-1}$ & & $\begin{array}{l}0.0660 \\
(0.110)\end{array}$ \\
\hline$\left(\Delta_{+} S P^{*} E(-1)\right)_{-2}$ & & $\begin{array}{l}-0.175 \\
(0.110)\end{array}$ \\
\hline$\Delta S P^{*} E(-1)$ & & $\begin{array}{l}0.298 * * * \\
(0.108)\end{array}$ \\
\hline$\left(\Delta S P^{*} E(-1)\right)_{-1}$ & & $\begin{array}{l}0.282 * * * \\
(0.108)\end{array}$ \\
\hline$\left(\Delta S P^{*} E(-1)\right)_{-2}$ & & $\begin{array}{l}-0.0438 \\
(0.0983)\end{array}$ \\
\hline$\Delta_{+} E^{*} S P(-1)$ & & $\begin{array}{l}0.940 * * * \\
(0.172)\end{array}$ \\
\hline$\left(\Delta_{+} E^{*} S P(-1)\right)_{-1}$ & & $\begin{array}{l}0.235 \\
(0.178)\end{array}$ \\
\hline$\left(\Delta_{+} E * S P(-1)\right)_{-2}$ & & $\begin{array}{l}0.118 \\
(0.182)\end{array}$ \\
\hline$\Delta E_{-1} * S P(-1)$ & & $\begin{array}{l}0.745^{* *} \\
(0.305)\end{array}$ \\
\hline$\left(\Delta E^{*} S P(-1)\right)_{-1}$ & & $\begin{array}{l}-0.0368 \\
(0.288)\end{array}$ \\
\hline$\left(\Delta E^{*} S P(-1)\right)_{-2}$ & & $\begin{array}{l}0.297 \\
(0.286)\end{array}$ \\
\hline$D-W$ & 1.91 & 1.93 \\
\hline Sum of squares & 8593.9 & 8269.5 \\
\hline $\operatorname{Adj} R 2$ & 0.711 & 0.711 \\
\hline NOBS & 178 & 178 \\
\hline
\end{tabular}




\section{Appendix 1}

Let the selection mechanism be

$$
Z^{*}=\delta^{\prime} \mathbf{W}+e
$$

where $Z^{*}$ is unobservable and the error term $e$ has a standard normal distribution. $\delta$ is a vector of parameters to be estimated and $\mathbf{W}$ a vector of explanatory variables (including a constant). $\mathrm{Z}$ can be observed according to

$$
Z=\left\{\begin{array}{cccc}
0 & \text { if } & Z^{*} \leq 0 & \text { "decrease price" } \\
1 & \text { if } & 0<Z^{*} \leq \mu_{1} & \text { "keep price constant " } \\
2 & \text { if } & \mu_{1} \leq Z^{*} & \text { "increase price" }
\end{array}\right.
$$

where $\mu_{1}$ is an additional parameter to be estimated. This specification states that the price is more likely to be decreased when $\delta^{\mathbf{W}}$ is small and increased when large. Let $\Phi($.$) denote the cumulative normal distribution to give the probabilities of the$ outcomes

$$
\operatorname{Prob}(Z=j)=\left\{\begin{array}{ccc}
\Phi\left(-\delta^{\prime} \mathbf{W}\right) & \text { for } & j=0 \\
\Phi\left(\mu_{1}-\delta^{\prime} \mathbf{W}\right)-\Phi\left(-\delta^{\prime} \mathbf{W}\right) & \text { for } & j=1 \\
1-\Phi\left(\mu_{1}-\delta^{\prime} \mathbf{W}\right) & \text { for } & j=2
\end{array}\right.
$$

The magnitude of the price change can be observed only when $j=0$ or $j=2$ and is then determined by the regression model

$$
\Delta R P=\beta_{j}^{\prime} \mathbf{X}_{j}+\varepsilon \quad \text { for } \mathrm{j}=0 \text { or } 2
$$


where $\beta$ is a vector of parameters and $\mathbf{X}$ explanatory variables which may be different for $\mathrm{j}=0$ and $\mathrm{j}=2$. The error terms $e$ and $\varepsilon$ is assumed to have a bivariate normal distribution $(0,0, \rho, 1, \sigma)$. The expectation of the error term $\varepsilon$ in (A4) is

$$
E[\varepsilon \mid Z=j]=\rho \sigma \lambda \quad \text { for } \mathrm{j}=0 \text { or } \mathrm{j}=2
$$

where $\lambda$ can be shown to be

$$
\lambda=\left\{\begin{array}{cc}
-\phi\left(-\delta^{\prime} \mathbf{W}\right) / \Phi\left(-\delta^{\prime} \mathbf{W}\right) & \text { for } \mathrm{j}=0 \\
\phi\left(\mu_{1}-\delta^{\prime} \mathbf{W}\right) /\left(1-\Phi\left(\mu_{1}-\delta^{\prime} \mathbf{W}\right)\right) & \text { for } \mathrm{j}=2
\end{array}\right.
$$

where $\phi($.$) is the normal distribution function. Thus the estimation of (A4) includes as$ an independent variable $\lambda$ estimated by (A1). 


\section{Appendix 2}

Table A. Tests for symmetric price responses to various cost changes.

\begin{tabular}{l|lllll}
\hline Model & Tab:Col & Frequency & SR/LR & Restriction & P-value \\
\hline OP & $5: 4$ & Daily & SR & $\Delta_{+} \mathrm{MC}=\Delta \mathrm{MC}$ & 0.4992 \\
OP & $6: 1$ & Daily & SR & $\Delta \mathrm{SP} * \mathrm{E}(-1)=\Delta \mathrm{E} * \mathrm{SP}(-1)$ & 0.1663 \\
OP & $6: 4$ & Daily & SR & $\Delta \mathrm{SP} * \mathrm{E}(-1)=\Delta \mathrm{E}^{*} \mathrm{SP}(-1)$ & 0.0241 \\
OP & $6: 4$ & Daily & LR & $\Delta \mathrm{SP} * \mathrm{E}(-1)=\Delta \mathrm{E} * \mathrm{SP}(-1)$ & 0.0658 \\
ECM & $7: 1$ & Monthly & LR & $\Delta \mathrm{TAX}=\Delta \mathrm{MC}$ & 0.8293 \\
ECM & $7: 2$ & Monthly & SR & $\Delta_{+} \mathrm{MC}=\Delta \mathrm{MC}$ & 0.0368 \\
ECM & $7: 2$ & Monthly & LR & $\Delta_{+} \mathrm{MC}=\Delta \mathrm{MC}$ & 0.9984 \\
ECM & $8: 1$ & Monthly & LR & $\Delta \mathrm{SP} * \mathrm{E}(-1)=\Delta \mathrm{TAX}$ & 0.0950 \\
ECM & $8: 1$ & Monthly & LR & $\Delta \mathrm{E}^{*} \mathrm{SP}(-1)=\Delta \mathrm{TAX}$ & 0.0270 \\
ECM & $8: 1$ & Monthly & SR & $\Delta \mathrm{SP} * \mathrm{E}(-1)=\Delta \mathrm{E} * \mathrm{SP}(-1)$ & 0.0039 \\
ECM & $8: 1$ & Monthly & LR & $\Delta \mathrm{SP} * \mathrm{E}(-1)=\Delta \mathrm{E} * \mathrm{SP}(-1)$ & 0.0026 \\
\hline
\end{tabular}

SR stands for short run (current coefficients), LR for long run (accumulated coefficients), OP for ordered probit and ECM for error correction model. 
Figure 1

Develoment of $R P$ and $M C+T A X$

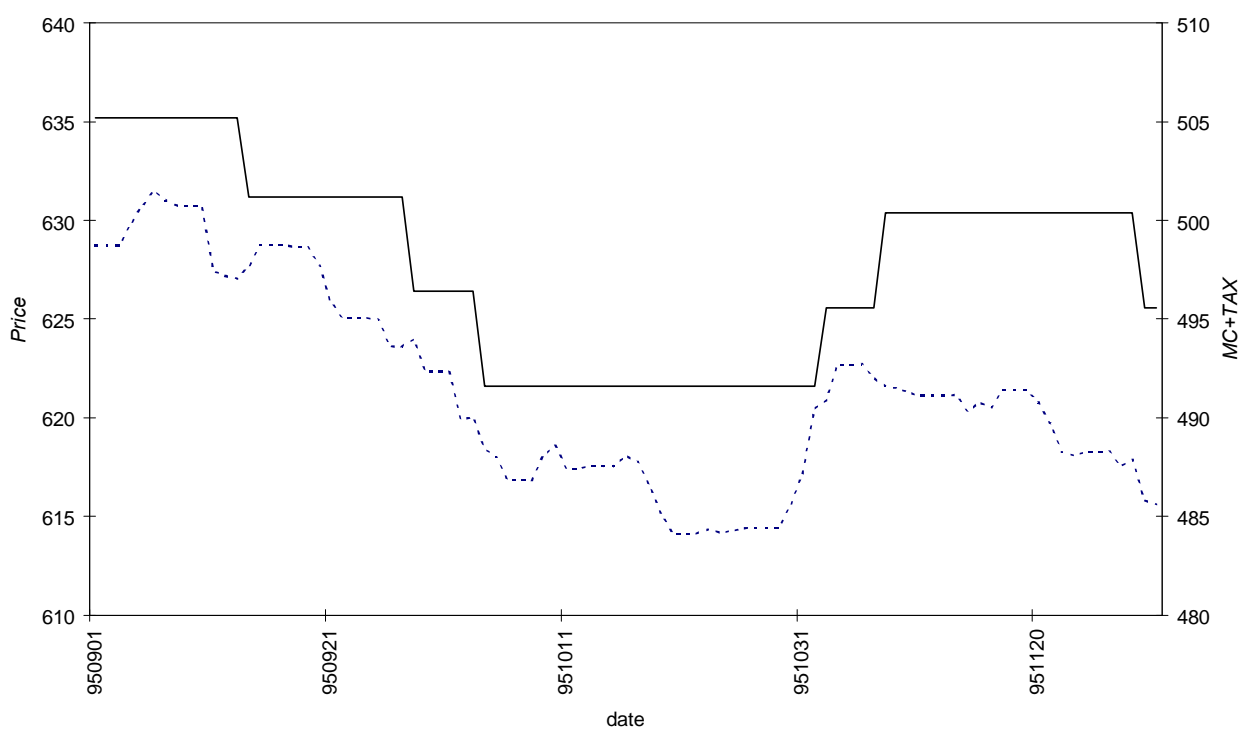


Figure 2

Difference between actual price and optimal price.

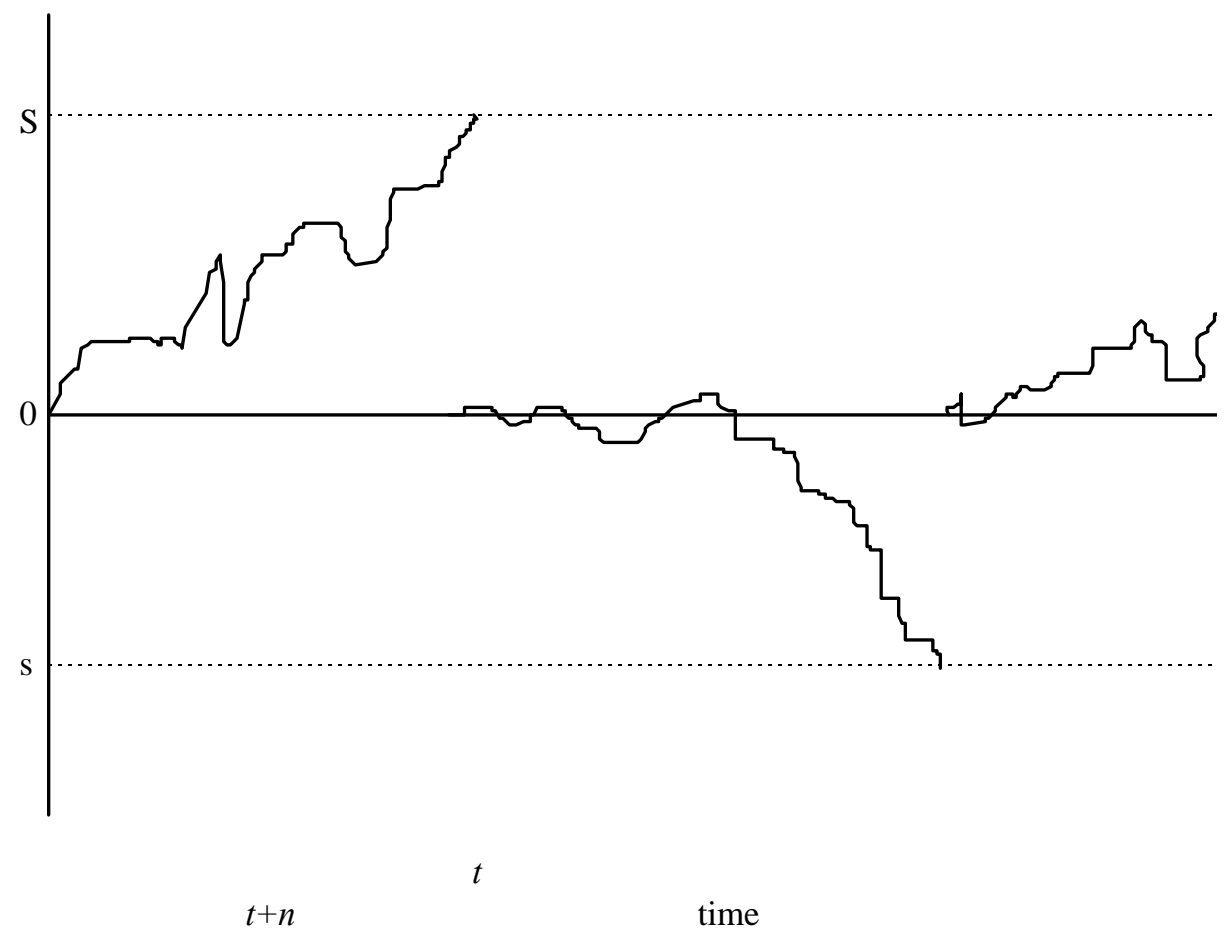


Figure 3

RP, MC, TAX

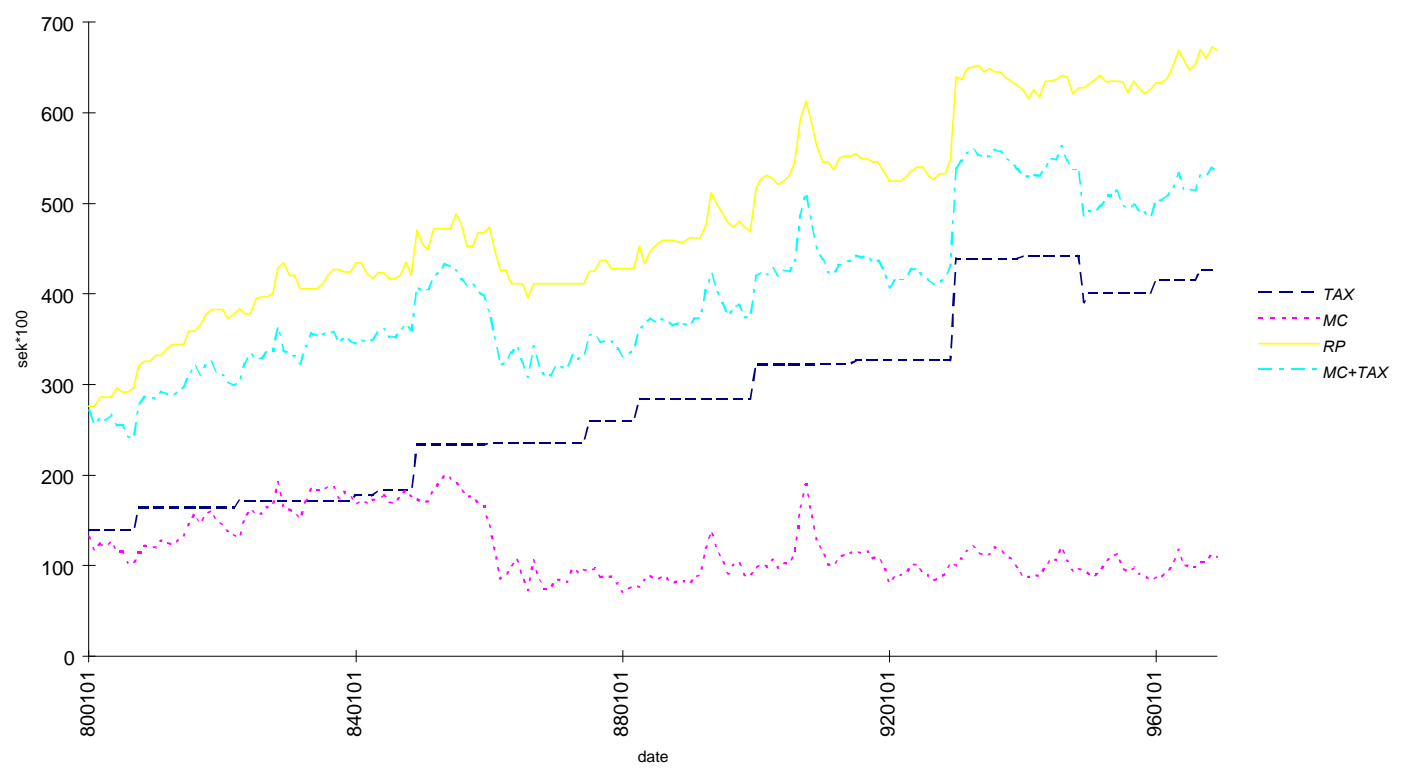


Figure 4

$R P$ and MC+TAX during the October 1993 price war

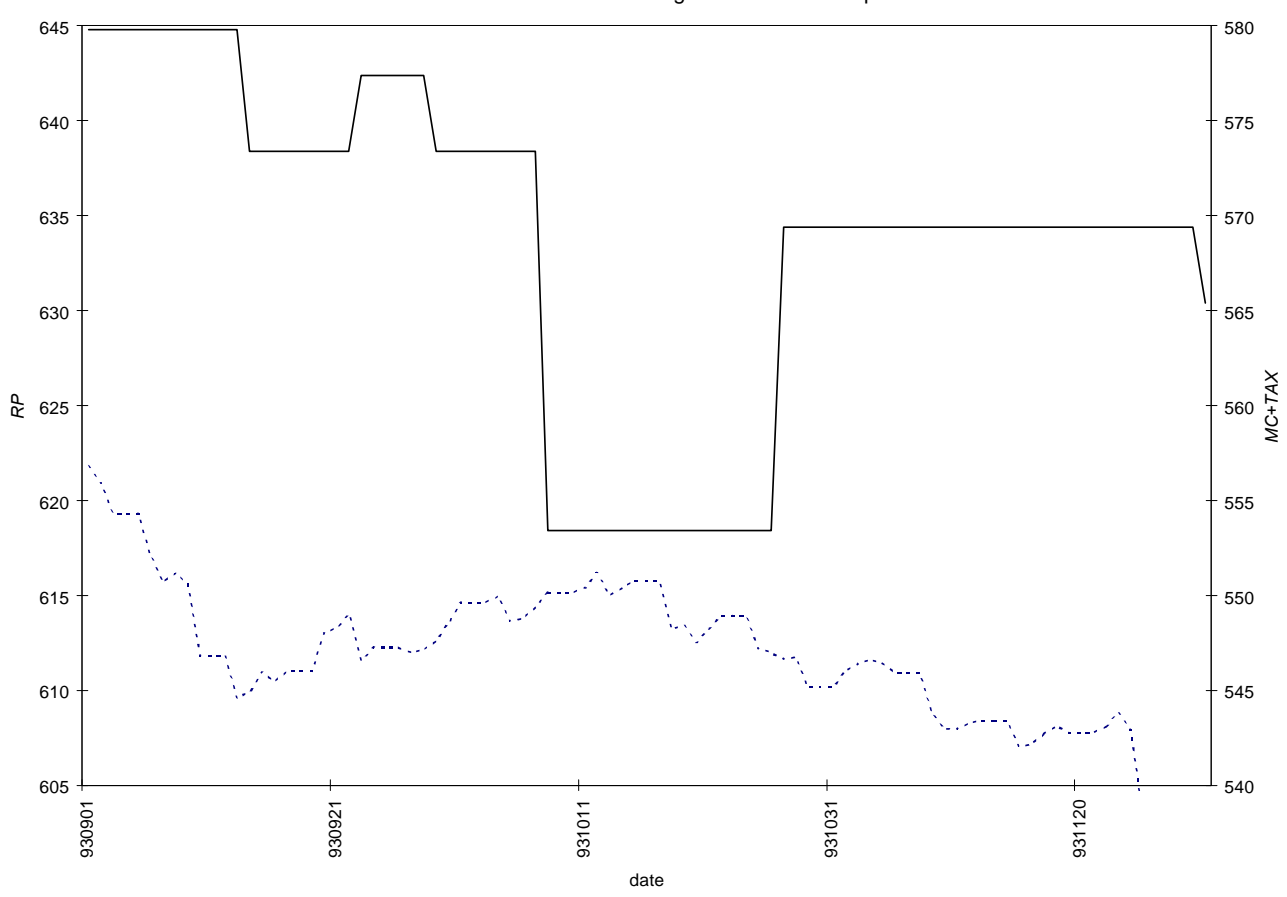


Figure 5

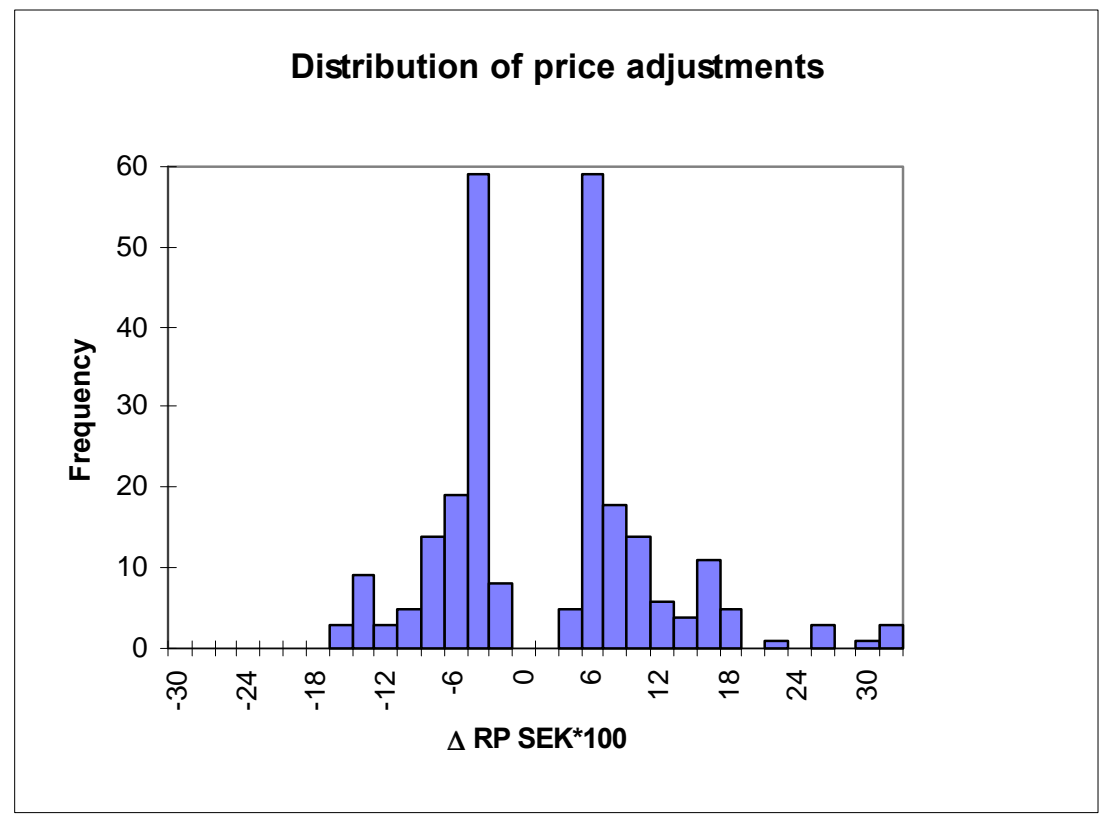




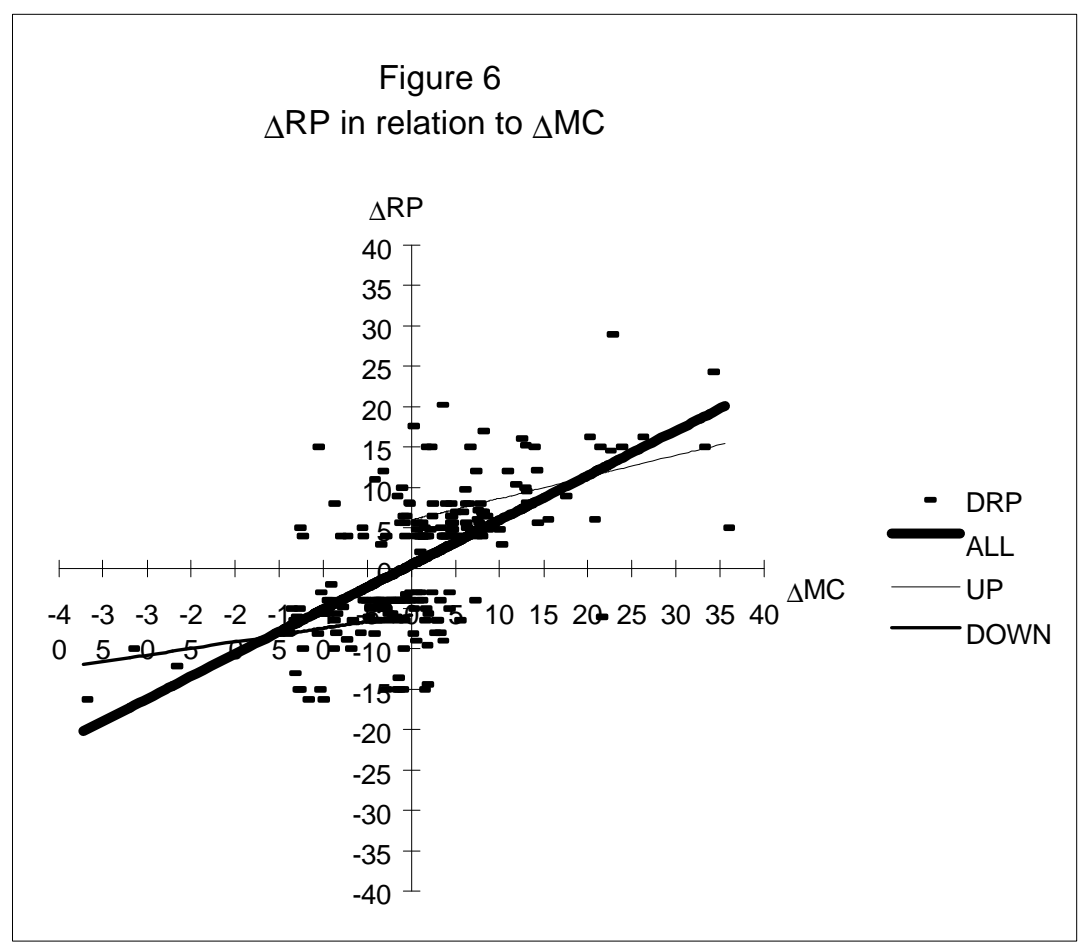

